\title{
Setores-chave da economia de Minas Gerais em 2008
}

\section{Carla Cristina Aguilar de Souza' Caio César Soares Gonçalves ${ }^{2}$ Marco Paulo Vianna Franco ${ }^{3}$}

\begin{abstract}
Resumo: Este trabalho teve como objetivo identificar setores-chave da economia mineira para o ano de 2008 e analisar o impacto dos diversos setores via cálculo de multiplicadores, contribuindo com ferramentas úteis à elaboração de políticas públicas. A partir da matriz de insumo-produto de 2008 e dos modelos aberto e fechado de Leontief, foi possível apontar setores-chave com base em três metodologias diferentes: índices de interligação de Rasmussen-Hirschman, campos de influência e índices puros de ligação. Em relação aos multiplicadores, foram abordados os impactos sobre a renda do trabalho, emprego, valor adicionado e impostos (ICMS e IPI).
\end{abstract}

Palavras-chave: Matriz de insumo-produto, Índices setoriais, Multiplicadores, Economia mineira.

Classificação JEL: E01; C67; R15.

Key sectors of the economy of Minas Gerais in 2008

\begin{abstract}
The aim of this article was to identify key sectors of the economy of Minas Gerais during 2008 and to analyze the impact of economic sectors through the calculation of sectoral multipliers, thus contributing with tools for the formulation of public policy. Based on the input-output matrix for 2008 and Leontief's open and closed models, key sectors could be identified using three different methodologies: Rasmussen-Hirschman's linkage indexes, fields of influence and pure linkage indexes. Sectoral multiplier analysis included impacts on labor, employment, added value and taxes (ICMS and IPI).
\end{abstract}

Key-words: Input-Output Matrix, Sectoral Indexes, Multiplier, Minas Gerais Economy.

JEL Classification: E01; C67; R15.

1 Pesquisadora em Ciência e Tecnologia da Fundação João Pinheiro - Centro de Estatística e Informações - Sistema de Contas Regionais.E-mail: carla.aguilar@fjp.mg.gov.br

2 Pesquisador em Ciência e Tecnologia da Fundação João Pinheiro - Centro de Estatística e Informações - Sistema de Contas Regionais. E-mail: caio.goncalves@fjp.mg.gov.br

3 Pesquisador em Ciência e Tecnologia da Fundação João Pinheiro - Centro de Estatística e Informações - Sistema de Contas Regionais; Doutorando em Economia pelo CEDEPLAR/UFMG. E-mail: marco.franco@fjp.mg.gov.br 


\section{Introdução}

Os setores da economia, de forma geral, não interagem entre si da mesma forma. Alguns transacionam com um grande número de setores, já outros podem se relacionar apenas com um grupo menor. No entanto, seja direta ou indiretamente, os efeitos de um setor podem repercutir em toda a cadeia produtiva. Nesse contexto, a análise de insumo-produto (LEONTIEF, 1936; 1941) é capaz de apontar características de uma dada estrutura produtiva cujo conhecimento pode conferir maior eficácia à elaboração de políticas públicas. Setores que possuem os maiores efeitos propulsores sobre a cadeia produtiva são conhecidos como setores-chave e, dado esse caráter significativamente multiplicador, constituem informação valiosa para o desenvolvimento de políticas econômicas. Tal abordagem se baseia, além do referencial teórico proposto por Leontief, nos trabalhos pioneiros de Rasmussen (1956) e Hirschman (1958) acerca da criação e análise de índices relativos aos encadeamentos entre os setores de uma dada economia.

A identificação de setores-chave via índices de encadeamento intersetorial e o cálculo de seus impactos sobre variáveis específicas, como emprego, renda, valor adicionado ou impostos, têm dado origem a inúmeros trabalhos com as mais diversas aplicações, tanto em âmbito nacional quanto estadual (NAJBERG e VIEIRA, 1996; HADDAD, 1999; MONTOYA, 1998; PORSSE, 2002; RAMOS, 2011).

O estudo de Fernandes \& Rocha (2010) identificou, a partir das matrizes insumo-produto de Minas Gerais, para o ano de 1996, elaborada pelo Banco de Desenvolvimento de Minas Gerais (BDMG) e para 2005, elaborada pela Fundação João Pinheiro, o setor de "Siderurgia e Metalurgia" como setor-chave nos dois anos e em todos os índices calculados, além de destacar as transformações sofridas por outros setores relevantes para a economia mineira, como os derivados de petróleo e álcool, a fabricação de produtos químicos e a fabricação de alimentos, que passaram a ser setores-chave no Estado na comparação entre os anos de 1996 e 2005. Os autores também destacaram as diferenças de agregação entre os dois anos analisados (são, no total, 42 setores para o ano de 1996 e 35 setores para o ano de 2005), algo que, novamente, acontece com a MIP de 2008, que apresenta desagregação da economia de Minas Gerais em 40 setores e que coloca certos limites à comparabilidade entre os três resultados. Mas, ainda assim, é válido comparar os resultados obtidos por Fernandes \& Rocha (2010) com os encontrados para a MIP de 2008, apresentados a seguir.

Para analisar a relação intersetorial em Minas Gerais ${ }^{4}$, o presente trabalho, a partir da matriz insumo-produto (MIP) de 2008 (FJP, 2015) e dos modelos aberto e fechado de Leontief (MILLER e BLAIR, 2009), busca identificar os setores-chave por meio de três diferentes perspectivas: aqueles com maior poder de encadeamen-

4 Kalluf e Kureski (2014) analisaram as relações intersetoriais da economia paranaense com metodologia e objetivos muito próximos ao deste trabalho. 
to (Índices de Rasmussen-Hirschman), aqueles que compõem os principais elos dentro da economia (Campo de Influência) e, também, aqueles que se destacam como os principais setores, levando em consideração o nível de produção (Índices Puros de Ligação). Além disso, o trabalho procura analisar impactos específicos dos diversos setores sobre a renda do trabalho, emprego, valor adicionado e impostos (ICMS e IPI) via cálculo de multiplicadores, contribuindo com ferramentas úteis à elaboração de políticas públicas.

Além dessa parte introdutória, apresentam-se na segunda seção as principais ferramentas utilizadas na literatura para identificar setores-chave de uma economia e a metodologia utilizada para o cálculo dos multiplicadores; a terceira seção aborda os resultados obtidos em cada abordagem dos índices e uma análise dos multiplicadores, e a última seção encerra o texto com uma conclusão.

\section{Metodologia}

Para obtenção dos índices setoriais e os multiplicadores, deriva-se, primeiramente, o modelo insumo-produto. Considerando que os fluxos intermediários do produto final são fixos, o sistema pode ser representado da seguinte forma matricial:

$$
A X+Y=X
$$

Em que A é a matriz de coeficientes diretos que indica a quantidade de insumo de um setor i necessária para produzir uma unidade de produto final do setor $\mathrm{j}$, ou seja, é calculada por meio da razão $\mathrm{a}_{\mathrm{ij}}=\mathrm{x}_{\mathrm{ij}} / \mathrm{x}_{\mathrm{j}}$; $\mathrm{x}$ é o vetor com os valores $\mathrm{da}$ produção total por setor i; e Y é a demanda final por setor i.

De forma a estabelecer a produção total necessária para atender a demanda final, isola-se a variável X:

$$
\begin{aligned}
& X=(I-A)^{-1} Y \\
& X=B Y
\end{aligned}
$$

em que $B=(I-A)^{-1}$ é a matriz de coeficientes técnicos diretos e indiretos, também chamada de matriz de Leontief. Os elementos dessa matriz podem ser interpretados como a produção total do setor $i$ necessária para produzir uma unidade de demanda final do setor $j$.

\subsection{Modelos aberto e fechado de Leontief}

Uma vez obtida a matriz de coeficientes técnicos diretos, a análise setorial pode ser feita de duas formas diferentes: utilizando o modelo aberto ou o modelo fechado. O modelo aberto se baseia na análise da matriz de Leontief, obtida direta- 
mente da matriz de coeficientes diretos, considerando os setores produtivos como endógenos e os elementos da demanda final como exógenos. Diz-se, então, que o modelo aberto leva em conta os efeitos diretos e indiretos provenientes somente da produção setorial.

A hipótese da exogeneidade dos elementos da demanda final é abandonada no modelo fechado. No caso mais comum, o consumo final das famílias é a parte da demanda final que se torna endógena, uma vez que a renda recebida na forma de salários e/ou rendimento misto bruto é utilizada na aquisição de bens e serviços, atuando como estímulo para o crescimento da produção e consequentemente do emprego. $\mathrm{O}$ modelo fechado em relação às famílias, assim, torna endógeno seu consumo final ao adicionar à matriz de coeficientes diretos uma linha e uma coluna relacionada ao consumo das famílias enquanto atividade econômica. Na linha constam os coeficientes formados pela divisão do valor adicionado dos salários e rendimento misto bruto pelo valor da produção bruta do setor; na coluna constam os coeficientes formados pela divisão do consumo setorial das famílias pelo consumo total das mesmas. Portanto, o modelo fechado inclui, além dos efeitos diretos e indiretos provenientes da produção setorial, o efeito induzido do consumo, também chamado de efeito renda. A nova matriz de coeficientes técnicos é obtida de acordo com a fórmula (4):

$$
\bar{A}=\left[\begin{array}{cc}
A & H_{C} \\
H_{R} & 0
\end{array}\right]
$$

na qual $A$ é a matriz de coeficientes diretos, $H_{C}$ é o vetor-coluna dos coeficientes de consumo setorial e $H_{R}$ é o vetor-linha dos coeficientes do valor, adicionado setorial dos salários e rendimento misto bruto. Finalmente, a matriz de coeficientes diretos e indiretos (ou matriz de Leontief) será dada por $(I-A)$ e o modelo fechado em relação às famílias será dado por:

$$
\bar{X}=(I-\bar{A})^{-1} \bar{f}, \operatorname{com} \bar{X}=\left[\begin{array}{c}
X \\
X_{n+1}
\end{array}\right] \text { e } \bar{f}=\left[\begin{array}{c}
f \\
f_{n+1}
\end{array}\right]
$$

em que $X$ é o vetor de produção por atividade e $f$ o vetor de demanda final.

\subsection{Setores-chave}

Para identificar os setores-chave da economia, adotaram-se as seguintes metodologias: os índices de interligação de Rasmussen-Hirschman conjuntamente com os índices de variabilidade, os campos de influência que enfocam na estrutura interna da economia; e os índices puros de ligação que, ao contrário dos dois primeiros, foca no nível de produção de cada setor. 


\subsection{1 Índices de interligação de Rasmussen-Hirschman}

$\mathrm{Na}$ tentativa de responder quais seriam os setores com o maior poder de encadeamento dentro da economia, os índices de interligação de Rasmussem-Hirschman medem os encadeamentos para trás (índice de poder de dispersão) e para frente (índice de sensibilidade à dispersão).

Para obter os índices de interligação, considera-se o sistema de equações representado em (1) e $B$ a matriz inversa de Leontief, definindo $b_{i j}$ como seus elementos e $B *$ como a média de todos os elementos de $B . B . j$ é a soma dos elementos da coluna $j$ e representa o efeito de encadeamento para trás e $B_{i}$ é a soma dos elementos da linha $i$. e evidencia o encadeamento para frente. Para retirar os efeitos da unidade de medida desses índices, faz-se uma normalização e obtém-se o índice de poder de dispersão (encadeamento para trás):

$$
U_{j}=\frac{\left(B_{. j} / n\right)}{B^{*}} \quad j=1,2, \ldots, n
$$

Como $U_{j}$ mede os encadeamentos para trás, seu valor representa o incremento total na produção da economia para cada aumento de uma unidade na demanda final do setor $j$. Dessa forma, se $U_{j}>1$, isso significa que a capacidade do setor em gerar efeitos para trás está acima da média do sistema. Caso $U_{j}<1$ a capacidade do setor em gerar efeitos para trás está abaixo da média do sistema, ou seja, o setor não é um importante demandante de insumos.

O índice de sensibilidade à dispersão (encadeamento para frente) é dado por:

$$
U_{i}=\frac{\left(B_{i .} / n\right)}{B^{*}} \quad i=1,2, \ldots, n
$$

Se $U_{i}>1$, a importância do setor enquanto fornecedor de insumos intermediários é superior à média dos demais setores, o que significa um poder de encadeamento para frente significativo. Se $U_{i}<1$, a importância do setor enquanto fornecedor de insumos intermediários é inferior à média dos demais setores - sendo assim, menos sensível que aqueles em relação às mudanças no sistema produtivo -, com poder de encadeamento para frente pouco significativo.

Os setores que possuem $U_{i}<1$ e $U_{j}<1$ são denominados independentes, pois não possuem relações fortes com os demais setores.

Um setor será considerado chave para o crescimento da economia se ambos os índices forem superiores a um. No entanto, como os valores desses índices se baseiam em médias e essas são muito sensíveis aos extremos, utilizam-se conjuntamente com esses índices as medidas de variabilidade propostas por Rasmussen: 


$$
\begin{array}{ll}
v_{. j}=\frac{\sqrt{\frac{1}{n-1} \sum_{i=1}^{n}\left[b_{i j}-\frac{1}{n} \sum_{i=1}^{n} b_{i j}\right]^{2}}}{\frac{1}{n} \sum_{i=1}^{n} b_{i j}}, & i, j=1,2, \ldots, n \\
v_{i .}=\frac{\sqrt{\frac{1}{n-1} \sum_{j=1}^{n}\left[b_{i j}-\frac{1}{n} \sum_{j=1}^{n} b_{i j}\right]^{2}}}{\frac{1}{n} \sum_{j=1}^{n} b_{i j}}, & i, j=1,2, \ldots, n
\end{array}
$$

Essas medidas de variabilidade possibilitam verificar se o setor se relaciona significativamente com poucos ou muitos setores. Se a variabilidade for baixa, significa que o setor tem um vínculo homogêneo ao sistema. Por outro lado, se a variabilidade for alta, o setor possui vínculo forte com poucos setores.

Assim, os setores considerados chave são aqueles que possuem os índices de dispersão e de sensibilidade à dispersão superiores a um e baixos valores de $v_{. j}$ e $v_{i .}$.

\subsubsection{Campos de influência}

Para complementar a análise dos índices de interligação, Sonis \& Hewings (1989) desenvolveram uma forma de mensurar os efeitos sinérgicos das alterações dos coeficientes da matriz, de forma a destacar as relações entre os setores mais influentes. Denominou-se essa abordagem de campos de influência.

A análise de campos de influência permite observar como as mudanças nos coeficientes diretos se distribuem no sistema econômico, sendo possível determinar quais as relações entre os setores que seriam mais influentes dentro do processo produtivo (GUILHOTO et al., 1994).

Para o cálculo dos campos de influência, consideram-se as seguintes matrizes:

$A=\left[a_{i j}\right]=$ matriz dos coeficientes diretos e $a_{i j}$ seus elementos;

$E=\left[\varepsilon_{i j}\right]=$ matriz de mudanças incrementais nos coeficientes diretos de insumos e $\varepsilon_{i j}$ seus elementos;

$B=(I-A)^{-1}=\left[b_{i j}\right]=$ matriz inversa de Leontief e $b_{i j}$ seus elementos;
$B(\varepsilon)=(I-A-E)^{-1}=\left[b_{i j}(\varepsilon)\right]=$ matriz inversa de Leontief após as mudanças e $b_{i j}(\varepsilon)$ seus elementos.

O campo de influência será aproximado pela diferença dos coeficientes da matriz de Leontief após e antes do choque, levando em consideração o incremento adicionado $(\varepsilon)$. A seguinte expressão representa a alteração:

$$
F\left(\varepsilon_{i j}\right)=\frac{\left[B\left(\varepsilon_{i j}\right)-B\right]}{\varepsilon}
$$


$F\left(\varepsilon_{i j}\right)$ é uma matriz $n \times n$ do campo de influência do coeficiente $a_{i j}$. E, assim, para comparar quais os setores com maior campo de influência, determina-se uma matriz $R_{i j}$ dada por:

$$
R_{i j}=\sum_{k=1}^{n} \sum_{l=1}^{n}\left[F_{k l}\left(\varepsilon_{i j}\right)\right]^{2}
$$

Os maiores valores de $R_{i j}$ apontam os setores que possuem maior campo de influência no sistema econômico. Assim, é possível identificar as relações setoriais com maiores impactos na economia, bem como se esses impactos são concentrados em poucos setores ou se são difundidos pela economia.

\subsection{3 Índices puros de ligação}

Sendo um dos métodos de identificação de setores-chave, os índices puros de ligação levam em conta o nível de produção na classificação dos setores com maior peso sobre a economia. Associado aos métodos que focam na estrutura interna da economia, propiciam uma análise mais detalhada e completa acerca do papel desempenhado por cada um dos setores no processo de crescimento econômico. O método consiste em isolar um dado setor $i$ e comparar a produção resultante com e sem suas relações intersetoriais em encadeamentos para trás e para frente, ou seja, seu papel como demandante de insumos e como fornecedor de insumos. Para tanto, subdivide-se a matriz de coeficientes diretos em duas partes: $A_{i}$, relacionada ao setor $i$ e $A_{r}$, relacionada ao resto da economia. Em forma matricial, fica:

$$
A=\left[\begin{array}{cc}
A_{i i} & A_{i r} \\
A_{r i} & A_{r r}
\end{array}\right]=\left[\begin{array}{cc}
A_{i i} & A_{i r} \\
A_{r i} & 0
\end{array}\right]+\left[\begin{array}{cc}
0 & 0 \\
0 & A_{r r}
\end{array}\right]=A_{i}+A_{r}
$$

Assim, a matriz de Leontief, sem considerar o setor $i$, será dada por $P_{1}=\left(I-A_{r}\right)^{-1}$; a matriz de Leontief considerando o efeito do setor $i$ sobre a economia enquanto demandante de insumos será dada por $P_{2}=\left(I-P_{1} A_{i}\right)^{-1}$; a matriz de Leontief, considerando o efeito do setor $i$ sobre a economia enquanto produtor será dada por $P_{3}=\left(I-A_{i} P_{1}\right)^{-1}$ e a matriz de Leontief original poderá ser obtida por meio da multiplicação de $P_{2}$ e $P_{1}$ ou, equivalentemente, de $P_{1}$ e $P_{3}$.

$O$ índice puro de ligação para trás pode, então, ser obtido a partir da coluna $\left(1-A_{r r}\right)^{-1} A_{r i}$ da matriz $P_{1} A_{i}$ excluindo-se a linha e coluna do setor $i$ (elementos $A_{i v}$, $A_{\text {ir }}$ e 0), como mostrado em (13): 


$$
P_{1} A_{i}=\left[\begin{array}{cc}
A_{i i} & A_{i r} \\
\left(1-A_{r r}\right)^{-1} A_{r i} & 0
\end{array}\right]
$$

Finalmente, somam-se os valores da coluna $\left(1-A_{r r}\right)^{-1} A_{r i}$ ao multiplicá-los por um vetor-linha de uns $v_{r r}$, de dimensão apropriada (número de setores menos um), e faz-se o produto do resultado pelo valor bruto de produção do setor $i\left(q_{i}\right)$, obtendose o índice puro de ligação para trás ("pure backward linkage", PBL) como mostrado em (14). Assim isola-se o impacto da produção do setor $i$ sobre a demanda por outros insumos da economia.

$$
P B L=v_{r r}\left(1-A_{r r}\right)^{-1} A_{r i} q_{i}
$$

O índice puro de ligação para frente, de forma análoga ao PBL, pode ser calculado a partir da linha $A_{i r}\left(1-A_{r r}\right)^{-1}$ da matriz $A_{i} P_{1}$ excluindo-se a linha e coluna do setor $i$ (elementos $A_{i i}, A_{r i}$ e 0), conforme a matriz apresentada em (15):

$$
A_{i} P_{1}=\left[\begin{array}{cc}
A_{i i} & A_{i r}\left(1-A_{r r}\right)^{-1} \\
A_{r i} & 0
\end{array}\right]
$$

Multiplicando os valores da linha $A_{i r}\left(1-A_{r r}\right)^{-1}$ pelo vetor-coluna do valor hruto de produção, cujo elemento correspondente ao setor $i$ tenha sido eliminado ( $q_{r} q_{r}$ ), obtém-se o índice puro de ligação para frente ("pure forward linkage", PFL) como mostrado na equação (16). Assim, isola-se o impacto da produção do resto da economia sobre a produção do setor $i$.

$$
P F L=A_{i r}\left(1-A_{r r}\right)^{-1} q_{r}
$$
PFL.

O índice puro de ligação total (PTL) é dado pela soma dos valores PBL e

\subsection{Multiplicadores}

Os multiplicadores de impacto são indicadores construídos a partir da matriz de insumo-produto, que auxiliam na identificação dos setores de maior influência sobre a economia. Os principais multiplicadores calculados permitem estimar, a partir de um aumento da demanda final, o impacto direto e indireto de cada setor da economia sobre a renda, o emprego, as importações, o valor adicionado, dentre outros. Os multiplicadores incorporam informações novas à 
análise de insumo-produto ao considerar os componentes do valor adicionado na equação básica do modelo.

Os multiplicadores são instrumentos enriquecedores no processo decisório de políticas públicas de desenvolvimento regional. Por exemplo, se o objetivo de uma política é o incentivo setorial com o propósito de impulsionar o emprego, o uso do multiplicador de impacto auxilia na identificação dos setores com maiores potencialidades para alcançar essa meta.

O multiplicador apresenta o impacto global de variações na demanda final do setor "j" sobre uma variável econômica de interesse. Esse efeito pode ser decomposto, de acordo com Feijó \& Ramos (2013), em:

a) Multiplicador total (direto e indireto) - mede o impacto da variação da demanda final do setor $i$, considerando as atividades que fornecem insumos diretos e indiretos para esse setor;

b) Multiplicador direto - mede o impacto da variação da demanda final do setor $j$, considerando apenas as atividades que fornecem insumos diretos para esse setor;

c) Multiplicador indireto - mede o impacto da variação da demanda final do setor $i$, considerando apenas as atividades que fornecem insumos indiretos para esse setor;

d) Multiplicador efeito-renda (induzido) - mede o impacto da variação da demanda final do setor $j$, considerando o efeito da variação adicional da demanda provocada pelo incremento no nível de rendimentos da economia quando um setor é estimulado.

O multiplicador do emprego, por exemplo, tem seu efeito inicial ${ }^{5}$ dado pelo total de pessoal ocupado por unidade de produto para cada setor da economia, expresso pela fórmula:

$$
e_{j}=\frac{E_{j}}{X_{j}}
$$

em que: $E_{j}=$ total de pessoal ocupado no setor $j$;

$X_{j}=$ valor da produção do setor $j$.

O multiplicador direto, conforme Feijó \& Ramos (2013), é dado por:

$$
e^{D}=e A
$$

\footnotetext{
Miller \& Blair (2009) denominam esse efeito como efeito inicial. É o impacto no emprego das atividades que aumentam sua produção, conforme colocado por Feijó \& Ramos (2013).
} 
em que: $A=$ matriz de coeficientes técnicos diretos;

$e=$ vetor dos efeitos iniciais.

O multiplicador total (direto e indireto) pode ser obtido pela multiplicação do vetor de efeito inicial pela matriz de impacto intersetorial do modelo aberto de Leontief. Assim, o multiplicador total é:

$$
e^{D I}=e(I-A)^{-1}
$$

em que: $e^{D I}=$ vetor do multiplicador direto e indireto do emprego;

$e=$ vetor dos efeitos iniciais;

$(I-A)^{-1}=$ matriz dos coeficientes técnicos do modelo aberto de Leontief.

O multiplicador indireto é a diferença do multiplicador total pelo multiplicador direto e o efeito inicial. Conforme equação (20):

$$
e^{I}=e^{D I}-e^{D}-e
$$

em que: $e^{I}=$ vetor do multiplicador indireto do emprego;

$e^{D I}=$ vetor do multiplicador direto e indireto do emprego;

$e^{D}=$ vetor do multiplicador direto do emprego.

O multiplicador direto, indireto e induzido é obtido multiplicando-se o multiplicador direto pela matriz do modelo fechado de Leontief.

$$
e^{D I R}=e^{D}(I-\bar{A})^{-1}
$$

em que: $e^{D I R}=$ vetor do multiplicador direto, indireto e induzido do emprego;

$e^{D}=$ vetor do multiplicador direto do emprego;

$(I-\bar{A})^{-1}=$ matriz dos coeficientes técnicos do modelo fechado de Leontief.

O multiplicador induzido é dado por:

$$
e^{R}=e^{D I R}-e^{D I}
$$

em que: $e^{D I R}=$ vetor do multiplicador direto, indireto e induzido do emprego; $e^{D I}=$ vetor do multiplicador direto e indireto do emprego. 
As mesmas funções podem ser utilizadas para calcular os multiplicadores para qualquer outra variável que compõe o valor adicionado. Neste estudo serão calculados os multiplicadores para renda, valor adicionado e impostos (ICMS e IPI), além do emprego.

\section{Análise dos Resultados}

Passa-se, agora, à análise dos resultados obtidos a partir da MIP da economia mineira para o ano de 2008, dividida em índices setoriais (incluindo a comparação entre índices) e multiplicadores.

\section{1 Índices Setoriais}

\subsection{1 Índices de interligação de Rasmussen-Hirschman}

Ao calcular os índices de encadeamento para frente $\left(B_{i}\right)$ e para trás $\left(B_{. j}\right)$, sem normalização, é possível observar a magnitude dos efeitos em unidades monetárias. $\mathrm{O}$ índice de ligação para frente indica quanto um setor é demandado dos outros quando ocorre um impacto de $\mathrm{R} \$ 1,00$ em todos os setores da economia. $\mathrm{O}$ índice de ligação para trás indica quanto determinado setor demanda dos demais quando sua demanda aumenta em $\mathrm{R} \$ 1,00$.

Ao calcular os mesmos índices para o modelo fechado (ao endogenizar o consumo das famílias), é possível extrair o efeito renda que é dado pela diferença dos valores obtidos no modelo fechado e aberto. A Tabela 1 indica os setores com os níveis mais altos de encadeamento para trás. Dentre esses, os que possuem maior efeito renda são: "Serviços domésticos"; "Pecuária e pesca"; "Administração pública"; "Álcool”; e "Artigos do vestuário e acessórios”. Por exemplo, um aumento na demanda de $\mathrm{R} \$ 1,00$ do setor "Pecuária e pesca" gera um impacto de $\mathrm{R} \$ 3,58$ em todos os setores da economia, sendo que $\mathrm{R} \$ 2,14$ são atribuídos ao efeito renda. O efeito renda desse setor é 1,5 vezes maior do que o efeito de encadeamento direto e indireto $(\mathrm{R} \$ 1,44)$.

Os setores com elevados índices de encadeamentos para frente estão apresentados na Tabela 2. O setor que possui maior impacto sobre sua própria demanda é o "Comércio" $(\mathrm{R} \$ 5,11)$. Os que possuem maior efeito renda são o "Comércio" e o setor de "Alimentos e bebidas". Por exemplo, um aumento na demanda de todos os setores da economia de R $\$ 1,00$ geraria um aumento na demanda do setor de "Alimentos e bebidas" de $\mathrm{R} \$ 3,89$, com $\mathrm{R} \$ 2,07$ atribuídos ao efeito renda, que é maior que o efeito direto e indireto $(\mathrm{R} \$ 1,82)$. 
Tabela 1: Encadeamentos para trás não normalizados, modelo aberto, modelo fechado e efeito renda - Minas Gerais - 2008.

\begin{tabular}{|c|c|c|c|c|c|}
\hline \multirow{2}{*}{ Código } & \multirow{2}{*}{ Atividade } & \multicolumn{3}{|c|}{$\mathrm{B}_{\mathrm{j}}$ (encadeamento para trás) } & \multirow{2}{*}{ Classificação } \\
\hline & & $\begin{array}{l}\text { Modelo } \\
\text { Aberto }\end{array}$ & $\begin{array}{l}\text { Efeito } \\
\text { Renda }\end{array}$ & $\begin{array}{l}\text { Modelo } \\
\text { Fechado }\end{array}$ & \\
\hline 101 & $\begin{array}{l}\text { Agricultura, silvicultura, } \\
\text { exploração florestal }\end{array}$ & 1,2731 & 1,8779 & 3,1509 & 8 \\
\hline 102 & Pecuária e pesca & 1,4430 & 2,1431 & 3,5862 & 2 \\
\hline 201 & Extrativa mineral & 1,4495 & 0,4597 & 1,9092 & 36 \\
\hline 301 & Alimentos e bebidas & 1,9313 & 1,3584 & 3,2897 & 5 \\
\hline 302 & Produtos do fumo & 1,0460 & 0,4494 & 1,4954 & 38 \\
\hline 303 & Têxteis & 1,4296 & 0,9915 & 2,4211 & 21 \\
\hline 304 & Artigos do vestuário e acessórios & 1,4637 & 1,3900 & 2,8538 & 13 \\
\hline 307 & Celulose e produtos de papel & 1,4314 & 0,5829 & 2,0143 & 35 \\
\hline 308 & Jornais, revistas, discos & 1,3253 & 0,9499 & 2,2752 & 27 \\
\hline 309 & Refino de petróleo e coque & 1,2139 & 0,2124 & 1,4263 & 39 \\
\hline 310 & Álcool & 1,7354 & 1,4490 & 3,1844 & 7 \\
\hline 311 & Produtos químicos & 1,6668 & 0,4926 & 2,1594 & 32 \\
\hline 313 & Produtos farmacêuticos & 1,6001 & 0,9660 & 2,5661 & 17 \\
\hline 314 & Defensivos agrícolas & 1,5842 & 0,6042 & 2,1884 & 30 \\
\hline 315 & Perfumaria, higiene e limpeza & 1,5237 & 0,7760 & 2,2997 & 26 \\
\hline 318 & Artigos de borracha e plástico & 1,4168 & 0,7468 & 2,1636 & 31 \\
\hline 319 & Cimento & 1,6868 & 0,6399 & 2,3267 & 25 \\
\hline 320 & $\begin{array}{l}\text { Outros produtos de minerais } \\
\text { não-metálicos }\end{array}$ & 1,6149 & 0,9363 & 2,5512 & 18 \\
\hline 321 & Fabricação de aço e derivados & 1,5588 & 0,4894 & 2,0482 & 33 \\
\hline 322 & Metalurgia de metais não ferrosos & 1,5913 & 0,6098 & 2,2010 & 29 \\
\hline 323 & $\begin{array}{l}\text { Produtos de metal exclusive } \\
\text { máquinas e equipamentos }\end{array}$ & 1,4952 & 0,8794 & 2,3747 & 22 \\
\hline 324 & $\begin{array}{l}\text { Máquinas e equipamentos, } \\
\text { inclusive manutenção e reparos }\end{array}$ & 1,4943 & 0,8354 & 2,3298 & 24 \\
\hline
\end{tabular}


(continua)

\begin{tabular}{|c|c|c|c|c|c|}
\hline 324 & $\begin{array}{c}\text { Máquinas e equipamentos, } \\
\text { inclusive manutenção e reparos }\end{array}$ & 1,4943 & 0,8354 & 2,3298 & 24 \\
\hline 325 & $\begin{array}{l}\text { Máquinas, equipamentos, } \\
\text { aparelhos eletroeletrônicos e } \\
\text { eletrodomésticos }\end{array}$ & 1,4857 & 0,7598 & 2,2455 & 28 \\
\hline 330 & $\begin{array}{c}\text { Fabricação de veículos } \\
\text { automotores }\end{array}$ & 1,5439 & 0,5017 & 2,0456 & 34 \\
\hline 332 & $\begin{array}{c}\text { Peças e acessórios para veículos } \\
\text { e outros equipamentos de } \\
\text { transporte }\end{array}$ & 1,5436 & 0,7918 & 2,3354 & 23 \\
\hline 334 & $\begin{array}{l}\text { Produtos de madeira, móveis e } \\
\text { produtos das indústrias diversas }\end{array}$ & 1,4698 & 0,9813 & 2,4510 & 20 \\
\hline 401 & $\begin{array}{c}\text { Produção e distribuição de } \\
\text { eletricidade, gás, água, esgoto e } \\
\text { limpeza urbana }\end{array}$ & 1,3262 & 0,5390 & 1,8652 & 37 \\
\hline 501 & Construção civil & 1,4155 & 1,2927 & 2,7083 & 14 \\
\hline 601 & Comércio & 1,2915 & 1,7148 & 3,0063 & 11 \\
\hline 701 & $\begin{array}{c}\text { Transporte, armazenagem e } \\
\text { correio }\end{array}$ & 1,3422 & 1,2436 & 2,5859 & 16 \\
\hline 801 & Serviços de informação & 1,5455 & 1,0823 & 2,6278 & 15 \\
\hline 901 & $\begin{array}{l}\text { Intermediação financeira, } \\
\text { seguros e previdência } \\
\text { complementar e serviços } \\
\text { relacionados }\end{array}$ & 1,3946 & 1,0856 & 2,4802 & 19 \\
\hline 1001 & $\begin{array}{c}\text { Atividades imobiliárias e } \\
\text { aluguéis }\end{array}$ & 1,0688 & 0,1762 & 1,2450 & 40 \\
\hline 1101 & $\begin{array}{l}\text { Serviços de manutenção e } \\
\text { reparação }\end{array}$ & 1,1728 & 1,8969 & 3,0697 & 9 \\
\hline 1102 & $\begin{array}{l}\text { Serviços de alojamento e } \\
\text { alimentação }\end{array}$ & 1,5912 & 1,4027 & 2,9939 & 12 \\
\hline 1103 & Serviços prestados às empresas & 1,3430 & 1,6765 & 3,0195 & 10 \\
\hline 1104 & $\begin{array}{c}\text { Educação mercantil e saúde } \\
\text { mercantil }\end{array}$ & 1,4045 & 2,0172 & 3,4217 & 4 \\
\hline 1106 & $\begin{array}{c}\text { Serviços prestados às famílias e } \\
\text { associativas }\end{array}$ & 1,4746 & 1,7170 & 3,1917 & 6 \\
\hline 1107 & Serviços domésticos & 1,0000 & 3,3624 & 4,3624 & 1 \\
\hline 1203 & Administração pública & 1,3011 & 2,1294 & 3,4305 & 3 \\
\hline
\end{tabular}


Tabela 2: Encadeamentos para frente não normalizados, modelo aberto, modelo fechado e efeito renda - Minas Gerais - 2008.

\begin{tabular}{|c|c|c|c|c|c|}
\hline \multirow{2}{*}{ Código } & \multirow{2}{*}{ Atividade } & \multicolumn{3}{|c|}{$\mathrm{B}_{\mathrm{j} j}$ (encadeamento para trás) } & \multirow{2}{*}{ Classificação } \\
\hline & & $\begin{array}{l}\text { Modelo } \\
\text { Aberto }\end{array}$ & $\begin{array}{l}\text { Efeito } \\
\text { Renda }\end{array}$ & $\begin{array}{l}\text { Modelo } \\
\text { Fechado }\end{array}$ & \\
\hline 101 & $\begin{array}{l}\text { Agricultura, silvicultura, } \\
\text { exploração florestal }\end{array}$ & 2,2791 & 0,9193 & 3,1984 & 8 \\
\hline 102 & Pecuária e pesca & 1,3924 & 0,5578 & 1,9502 & 15 \\
\hline 201 & Extrativa mineral & 1,4827 & 0,0315 & 1,5142 & 20 \\
\hline 301 & Alimentos e bebidas & 1,8178 & 2,0753 & 3,8931 & 3 \\
\hline 302 & Produtos do fumo & 1,0264 & 0,1636 & 1,1900 & 35 \\
\hline 303 & Têxteis & 1,2221 & 0,0679 & 1,2900 & 26 \\
\hline 304 & $\begin{array}{l}\text { Artigos do vestuário e } \\
\text { acessórios }\end{array}$ & 1,0771 & 0,4460 & 1,5231 & 19 \\
\hline 307 & Celulose e produtos de papel & 1,1546 & 0,0371 & 1,1916 & 34 \\
\hline 308 & Jornais, revistas, discos & 1,1393 & 0,1354 & 1,2748 & 28 \\
\hline 309 & Refino de petróleo e coque & 1,7668 & 0,6343 & 2,4011 & 12 \\
\hline 310 & Álcool & 1,1029 & 0,1003 & 1,2032 & 33 \\
\hline 311 & Produtos químicos & 2,4383 & 0,2335 & 2,6718 & 10 \\
\hline 313 & Produtos farmacêuticos & 1,0096 & 0,0538 & 1,0634 & 40 \\
\hline 314 & Defensivos agrícolas & 1,1508 & 0,0303 & 1,1811 & 37 \\
\hline 315 & Perfumaria, higiene e limpeza & 1,0153 & 0,0590 & 1,0742 & 39 \\
\hline 318 & Artigos de borracha e plástico & 1,1905 & 0,0659 & 1,2564 & 31 \\
\hline 319 & Cimento & 1,1184 & 0,0156 & 1,1340 & 38 \\
\hline 320 & $\begin{array}{l}\text { Outros produtos de minerais } \\
\text { não-metálicos }\end{array}$ & 1,2814 & 0,0510 & 1,3324 & 25 \\
\hline 321 & Fabricação de aço e derivados & 1,7733 & 0,0592 & 1,8325 & 16 \\
\hline 322 & $\begin{array}{l}\text { Metalurgia de metais não } \\
\text { ferrosos }\end{array}$ & 1,1710 & 0,0154 & 1,1863 & 36 \\
\hline 323 & $\begin{array}{l}\text { Produtos de metal exclusive } \\
\text { máquinas e equipamentos }\end{array}$ & 1,2887 & 0,0620 & 1,3507 & 24 \\
\hline
\end{tabular}


(continua)

\begin{tabular}{|c|c|c|c|c|c|}
\hline 324 & $\begin{array}{l}\text { Máquinas e equipamentos, } \\
\text { inclusive manutenção e reparos }\end{array}$ & 1,1802 & 0,0257 & 1,2059 & 32 \\
\hline 325 & $\begin{array}{c}\text { Máquinas, equipamentos, } \\
\text { aparelhos eletroeletrônicos e } \\
\text { eletrodomésticos }\end{array}$ & 1,2189 & 0,1371 & 1,3560 & 23 \\
\hline 330 & $\begin{array}{l}\text { Fabricação de veículos } \\
\text { automotores }\end{array}$ & 1,0327 & 0,3240 & 1,3567 & 22 \\
\hline 332 & $\begin{array}{c}\text { Peças e acessórios para veículos } \\
\text { e outros equipamentos de } \\
\text { transporte }\end{array}$ & 1,3423 & 0,0972 & 1,4395 & 21 \\
\hline 334 & $\begin{array}{l}\text { Produtos de madeira, móveis e } \\
\text { produtos das indústrias diversas }\end{array}$ & 1,1461 & 0,1345 & 1,2806 & 27 \\
\hline 401 & $\begin{array}{c}\text { Produção e distribuição de } \\
\text { eletricidade, gás, água, esgoto e } \\
\text { limpeza urbana }\end{array}$ & 2,1798 & 1,0970 & 3,2768 & 6 \\
\hline 501 & Construção civil & 1,1421 & 0,1272 & 1,2694 & 29 \\
\hline 601 & Comércio & 2,7621 & 2,3442 & 5,1063 & 1 \\
\hline 701 & $\begin{array}{l}\text { Transporte, armazenagem e } \\
\text { correio }\end{array}$ & 2,0227 & 0,9116 & 2,9343 & 9 \\
\hline 801 & Serviços de informação & 2,0545 & 1,1765 & 3,2310 & 7 \\
\hline 901 & $\begin{array}{l}\text { Intermediação financeira, } \\
\text { seguros e previdência } \\
\text { complementar e serviços } \\
\text { relacionados }\end{array}$ & 1,9434 & 1,6821 & 3,6255 & 5 \\
\hline 1001 & $\begin{array}{l}\text { Atividades imobiliárias e } \\
\text { aluguéis }\end{array}$ & 1,5054 & 2,9180 & 4,4234 & 2 \\
\hline 1101 & $\begin{array}{l}\text { Serviços de manutenção e } \\
\text { reparação }\end{array}$ & 1,1404 & 0,3872 & 1,5275 & 17 \\
\hline 1102 & $\begin{array}{l}\text { Serviços de alojamento e } \\
\text { alimentação }\end{array}$ & 1,1420 & 1,1539 & 2,2958 & 13 \\
\hline 1103 & Serviços prestados às empresas & 2,7150 & 1,0182 & 3,7333 & 4 \\
\hline 1104 & $\begin{array}{l}\text { Educação mercantil e saúde } \\
\text { mercantil }\end{array}$ & 1,0221 & 1,4007 & 2,4228 & 11 \\
\hline 1106 & $\begin{array}{c}\text { Serviços prestados às famílias e } \\
\text { associativas }\end{array}$ & 1,1289 & 0,8900 & 2,0189 & 14 \\
\hline 1107 & Serviços domésticos & 1,0000 & 0,5237 & 1,5237 & 18 \\
\hline 1203 & Administração pública & 1,1128 & 0,1551 & 1,2679 & 30 \\
\hline
\end{tabular}


Os índices de encadeamento para frente e para trás normalizados permitem tornar os índices independentes das unidades de medida. Nesse caso, não se considera a importância de cada setor na estrutura da demanda final e, com isso, é possível identificar os setores independentes $\left(\mathrm{U}_{\mathrm{i}}<1, \mathrm{U}_{\mathrm{j},}<1\right)$, os apenas com efeito de dispersão $\left(U_{i}<1, U_{. j}>1\right)$, os apenas com efeito de sensibilidade à dispersão $\left(U_{i}>1\right.$, $\left.\mathrm{U}_{. \mathrm{j}}<1\right)$ e os setores-chave da economia $\left(\mathrm{U}_{\mathrm{i} .}>1, \mathrm{U}_{\mathrm{j}}>1\right)$.

Os setores considerados independentes (Tábela 3), de acordo com os dados de Minas Gerais, em 2008, são: "Produtos do fumo", "Têxteis", "Celulose e produtos de papel", "Jornais, revistas, discos", "Artigos de borracha e plástico", "Construção civil", "Serviços de manutenção e reparação", "Educação mercantil e saúde mercantil", "Serviços domésticos" e "Administração pública". Todos esses setores também possuem vínculo com poucos setores, pois os $v_{j}$ e $v_{i}$ são altos.

Tabela 3: Setores Independentes - Índices de Rasmussen-Hirschman e Variabilidade - Minas Gerais, 2008.

\begin{tabular}{c|c|c|c|c|c}
\hline Código & Atividade & $\mathrm{U}_{. j}$ & $\mathrm{v}_{\mathrm{j}}$ & $\mathrm{U}_{\mathrm{i} .}$ & $\mathrm{v}_{\mathrm{i} .}$ \\
\hline 302 & Produtos do fumo & 0,7252 & 6,2006 & 0,7116 & 6,4186 \\
\hline 303 & Têxteis & 0,9912 & 4,7075 & 0,8474 & 5,5877 \\
\hline 307 & Celulose e produtos de papel & 0,9925 & 4,6894 & 0,8005 & 5,8908 \\
\hline 308 & Jornais, revistas, discos & 0,9189 & 4,8628 & 0,7900 & 5,7315 \\
\hline 318 & Artigos de borracha e plástico & 0,9824 & 4,5116 & 0,8254 & 5,4118 \\
\hline 501 & Construção civil & 0,9815 & 4,5318 & 0,7919 & 5,6961 \\
\hline 1101 & Serviços de manutenção e reparação & 0,8132 & 5,3864 & 0,7907 & 5,6019 \\
\hline 1104 & $\begin{array}{c}\text { Educação mercantil e saúde } \\
\text { mercantil }\end{array}$ & 0,9738 & 4,4860 & 0,7087 & 6,2873 \\
\hline 1107 & Serviços domésticos & 0,6934 & 6,3246 & 0,6934 & 6,4306 \\
\hline 1203 & Administração pública & 0,9022 & 4,8552 & 0,7715 & 5,7562 \\
\hline
\end{tabular}

Os setores com alto poder de dispersão, fortes ligações para trás e baixa sensibilidade à dispersão estão apresentados na Tabela 4. Como esses são setores dependentes da oferta intersetorial, um estimulo à sua produção tem um impacto sobre um número maior de setores da economia mineira. Desses setores, destacam-se os setores de "Álcool", "Produtos farmacêuticos", "Cimento" e "Outros produtos de minerais não metálicos" por possuírem os menores valores de variabilidade e, logo, um vínculo mais homogêneo na economia. 
Tabela 4: Setores com maior poder de dispersão - Índices de RasmussenHirschman e Variabilidade- Minas Gerais - 2008.

\begin{tabular}{|c|c|c|c|c|c|}
\hline Código & Atividade & $U_{. j}$ & $\mathrm{v}_{. j}$ & $\mathrm{U}_{\mathrm{i} .}$ & $\mathrm{v}_{\mathrm{i} .}$ \\
\hline 102 & Pecuária e pesca & 1,0005 & 4,6136 & 0,9654 & 4,8473 \\
\hline 304 & Artigos do vestuário e acessórios & 1,0149 & 4,5648 & 0,7468 & 6,2904 \\
\hline 310 & Álcool & 1,2033 & 3,8607 & 0,7647 & 5,8065 \\
\hline 313 & Produtos farmacêuticos & 1,1094 & 3,9483 & 0,7000 & 6,3876 \\
\hline 314 & Defensivos agrícolas & 1,0984 & 4,2569 & 0,7979 & 5,9360 \\
\hline 315 & Perfumaria, higiene e limpeza & 1,0565 & 4,1544 & 0,7040 & 6,3518 \\
\hline 319 & Cimento & 1,1695 & 3,8383 & 0,7755 & 5,8871 \\
\hline 320 & $\begin{array}{l}\text { Outros produtos de minerais não- } \\
\text { metálicos }\end{array}$ & 1,1197 & 4,0490 & 0,8885 & 5,1665 \\
\hline 322 & Metalurgia de metais não ferrosos & 1,1033 & 4,0791 & 0,8119 & 5,6140 \\
\hline 323 & $\begin{array}{l}\text { Produtos de metal exclusive } \\
\text { máquinas e equipamentos }\end{array}$ & 1,0367 & 4,3435 & 0,8935 & 5,0608 \\
\hline 324 & $\begin{array}{c}\text { Máquinas e equipamentos, inclusive } \\
\text { manutenção e reparos }\end{array}$ & 1,0361 & 4,2508 & 0,8183 & 5,4456 \\
\hline 325 & $\begin{array}{l}\text { Máquinas, equipamentos, aparelhos } \\
\text { eletroeletrônicos e eletrodomésticos }\end{array}$ & 1,0301 & 4,4743 & 0,8452 & 5,5153 \\
\hline 330 & Fabricação de veículos automotores & 1,0705 & 4,1691 & 0,7160 & 6,3371 \\
\hline 332 & $\begin{array}{l}\text { Peças e acessórios para veículos e } \\
\text { outros equipamentos de transporte }\end{array}$ & 1,0703 & 4,4879 & 0,9307 & 5,2181 \\
\hline 334 & $\begin{array}{l}\text { Produtos de madeira, móveis e } \\
\text { produtos das indústrias diversas }\end{array}$ & 1,0191 & 4,6292 & 0,7947 & 6,0308 \\
\hline 1102 & $\begin{array}{l}\text { Serviços de alojamento e } \\
\text { alimentação }\end{array}$ & 1,1033 & 4,0521 & 0,7918 & 5,6231 \\
\hline
\end{tabular}

As atividades que possuem maior sensibilidade de dispersão e são impactadas acima da média quando ocorre uma ampliação da demanda final, estão apresentados na Tabela 5. Esses setores são importantes fornecedores de insumos na economia mineira. Os mais dinâmicos são "Comércio" e "Serviços prestados às empresas", por possuírem os maiores índices de sensibilidade à dispersão e menores variabilidades. 
Tabela 5: Setores com maior sensibilidade de dispersão- Índices de RasmussenHirschman e Variabilidade - Minas Gerais - 2008.

\begin{tabular}{|c|c|c|c|c|c|}
\hline Código & Atividade & U.j & v.j & Ui. & vi. \\
\hline 101 & $\begin{array}{c}\text { Agricultura, silvicultura, exploração } \\
\text { florestal }\end{array}$ & 0,8827 & 5,0862 & 1,5802 & 3,0069 \\
\hline 309 & Refino de petróleo e coque & 0,8417 & 5,2292 & 1,2250 & 3,5501 \\
\hline 401 & $\begin{array}{c}\text { Produção e distribuição de } \\
\text { eletricidade, gás, água, esgoto e } \\
\text { limpeza urbana }\end{array}$ & 0,9196 & 5,5446 & 1,5114 & 3,2941 \\
\hline 601 & Comércio & 0,8955 & 5,0766 & 1,9152 & 2,3008 \\
\hline 701 & Transporte, armazenagem e correio & 0,9306 & 4,9051 & 1,4025 & 3,1716 \\
\hline 901 & $\begin{array}{c}\text { Intermediação financeira, seguros } \\
\text { e previdência complementar e } \\
\text { serviços relacionados }\end{array}$ & 0,9669 & 5,0343 & 1,3475 & 3,5400 \\
\hline 1001 & Atividades imobiliárias e aluguéis & 0,7411 & 5,9296 & 1,0438 & 4,1717 \\
\hline 1103 & Serviços prestados às empresas & 0,9312 & 5,2984 & 1,8825 & 2,5314 \\
\hline
\end{tabular}

Os setores-chave, aqueles com índices de dispersão e de sensibilidade à dispersão maiores que um, são: "Extrativa mineral", "Alimentos e bebidas", "Produtos químicos", "Fabricação de aço e derivados" e "Serviços de informação" (Tabela 6). Esses setores são importantes para a economia de Minas Gerais, tanto como fornecedores de insumos como geradores de estímulo aos outros setores.

Tabela 6: Setores-chave- Índices de Rasmussen-Hirschman e Variabilidade Minas Gerais - 2008

\begin{tabular}{c|c|c|c|c|c}
\hline Código & Atividade & $\mathrm{U}_{. j}$ & $\mathrm{v}_{\mathrm{j}}$ & $\mathrm{U}_{\mathrm{i} .}$ & $\mathrm{v}_{\mathrm{i} .}$ \\
\hline 201 & Extrativa mineral & 1,0050 & 4,6831 & 1,0280 & 4,5919 \\
\hline 301 & Alimentos e bebidas & 1,3391 & 3,9668 & 1,2604 & 4,1718 \\
\hline 311 & Produtos químicos & 1,1557 & 4,7856 & 1,6906 & 3,2228 \\
\hline 321 & Fabricação de aço e derivados & 1,0808 & 4,3863 & 1,2295 & 3,8718 \\
\hline 801 & Serviços de informação & 1,0716 & 4,9743 & 1,4245 & 3,6745 \\
\hline
\end{tabular}




\subsubsection{Campos de influência}

O objetivo dos campos de influência é identificar os setores que possuem as mais importantes relações com os demais setores. Para isso, definiu-se um incremento $\varepsilon=0,001$ nos coeficientes técnicos diretos e verificou a alteração nos demais setores calculando uma medida síntese que representa, em termos numéricos, a mudança ocorrida em toda a economia (matriz $R_{i j}$ ) - conforme metodologia já abordada.

A Tabela 7 apresenta as relações intersetoriais mais influentes dentro do processo produtivo da economia mineira para o ano de 2008. Para elencar os principais elos intersetoriais, utilizaram-se como critério os $10 \%$ maiores valores da matriz $R_{i j}$ . Do total de 1600 elementos, os 160 primeiros foram considerados mais influentes. O setor de "Produtos químicos" registrou o maior destaque com efeito propagador sobre 40 setores referentes à compra de insumos e 33 setores referentes às vendas.

Tabela 7: Número de relações setoriais do campo de influência por vendas e compras.

\begin{tabular}{c|c|c|c}
\hline Código & Atividade & $\begin{array}{c}\text { Vendas/ } \\
\text { linhas }\end{array}$ & $\begin{array}{c}\text { Compras/ } \\
\text { colunas }\end{array}$ \\
\hline 101 & Agricultura, silvicultura, exploração florestal & 1 & 5 \\
\hline 102 & Pecuária e pesca & 3 & 3 \\
\hline 201 & Extrativa mineral & 4 & 3 \\
\hline 301 & Alimentos e bebidas & 20 & 18 \\
\hline 302 & Produtos do fumo & 1 & 1 \\
\hline 303 & Têxteis & 3 & 3 \\
\hline 304 & Artigos do vestuário e acessórios & 3 & 3 \\
\hline 307 & Celulose e produtos de papel & 1 & 3 \\
\hline 308 & Jornais, revistas, discos & 1 & 1 \\
\hline 309 & Refino de petróleo e coque & 3 & 0 \\
\hline 310 & Álcool & 33 & 40 \\
\hline 311 & Produtos químicos & 1 & 0 \\
\hline 313 & Produtos farmacêuticos & 3 & 3 \\
\hline 314 & Defensivos agrícolas & 1 & 0 \\
\hline 315 & Perfumaria, higiene e limpeza & 3 \\
\hline 318 & Cimento & 3 & 1 \\
\hline 319 & & continua)
\end{tabular}


(continua)

\begin{tabular}{|c|c|c|c|}
\hline 321 & Fabricação de aço e derivados & 4 & 4 \\
\hline 322 & Metalurgia de metais não ferrosos & 2 & 1 \\
\hline 323 & Produtos de metal exclusive máquinas e equipamentos & 2 & 1 \\
\hline 324 & Máquinas e equipamentos, inclusive manutenção e reparos & 1 & 1 \\
\hline 325 & $\begin{array}{l}\text { Máquinas, equipamentos, aparelhos eletroeletrônicos e } \\
\text { eletrodomésticos }\end{array}$ & 3 & 3 \\
\hline 330 & Fabricação de veículos automotores & 1 & 1 \\
\hline 332 & $\begin{array}{l}\text { Peças e acessórios para veículos e outros equipamentos de } \\
\text { transporte }\end{array}$ & 5 & 4 \\
\hline 334 & Produtos de madeira, móveis e produtos das indústrias diversas & 4 & 3 \\
\hline 401 & $\begin{array}{l}\text { Produção e distribuição de eletricidade, gás, água, esgoto e } \\
\text { limpeza urbana }\end{array}$ & 9 & 10 \\
\hline 501 & Construção civil & 1 & 1 \\
\hline 601 & Comércio & 2 & 3 \\
\hline 701 & Transporte, armazenagem e correio & 2 & 3 \\
\hline 801 & Serviços de informação & 19 & 23 \\
\hline 901 & $\begin{array}{l}\text { Intermediação financeira, seguros e previdência complementar e } \\
\text { serviços relacionados }\end{array}$ & 5 & 4 \\
\hline 1001 & Atividades imobiliárias e aluguéis & 1 & 1 \\
\hline 1101 & Serviços de manutenção e reparação & 1 & 0 \\
\hline 1102 & Serviços de alojamento e alimentação & 1 & 1 \\
\hline 1103 & Serviços prestados às empresas & 6 & 7 \\
\hline 1104 & Educação mercantil e saúde mercantil & 1 & 0 \\
\hline 1106 & Serviços prestados às famílias e associativas & 1 & 1 \\
\hline 1107 & Serviços domésticos & 1 & 0 \\
\hline 1203 & Administração pública & 1 & 0 \\
\hline
\end{tabular}

Sob o ponto de vista apenas dos vendedores de insumos, o setor de "Alimentos e bebidas" registrou 20 das maiores propagações sobre os outros setores, seguido do setor de "Serviços de informação" com 19, "Produção e distribuição de eletricidade, gás, água, esgoto e limpeza urbana" com 9 e "Serviços prestados às empresas" com 6. No lado da compra de insumos, "Serviços de informação" aparece em segundo com 23, "Alimentos e bebidas" com 18, "Produção e distribuição de eletricidade, gás, água, esgoto e limpeza urbana" com 10 e "Serviços prestados às empresas" com 7. O Gráfico 1 representa o campo de influência com as 160 maiores ligações. 
Gráfico 1: Campo de influência da matriz de insumo-produto de Minas Gerais 2008.

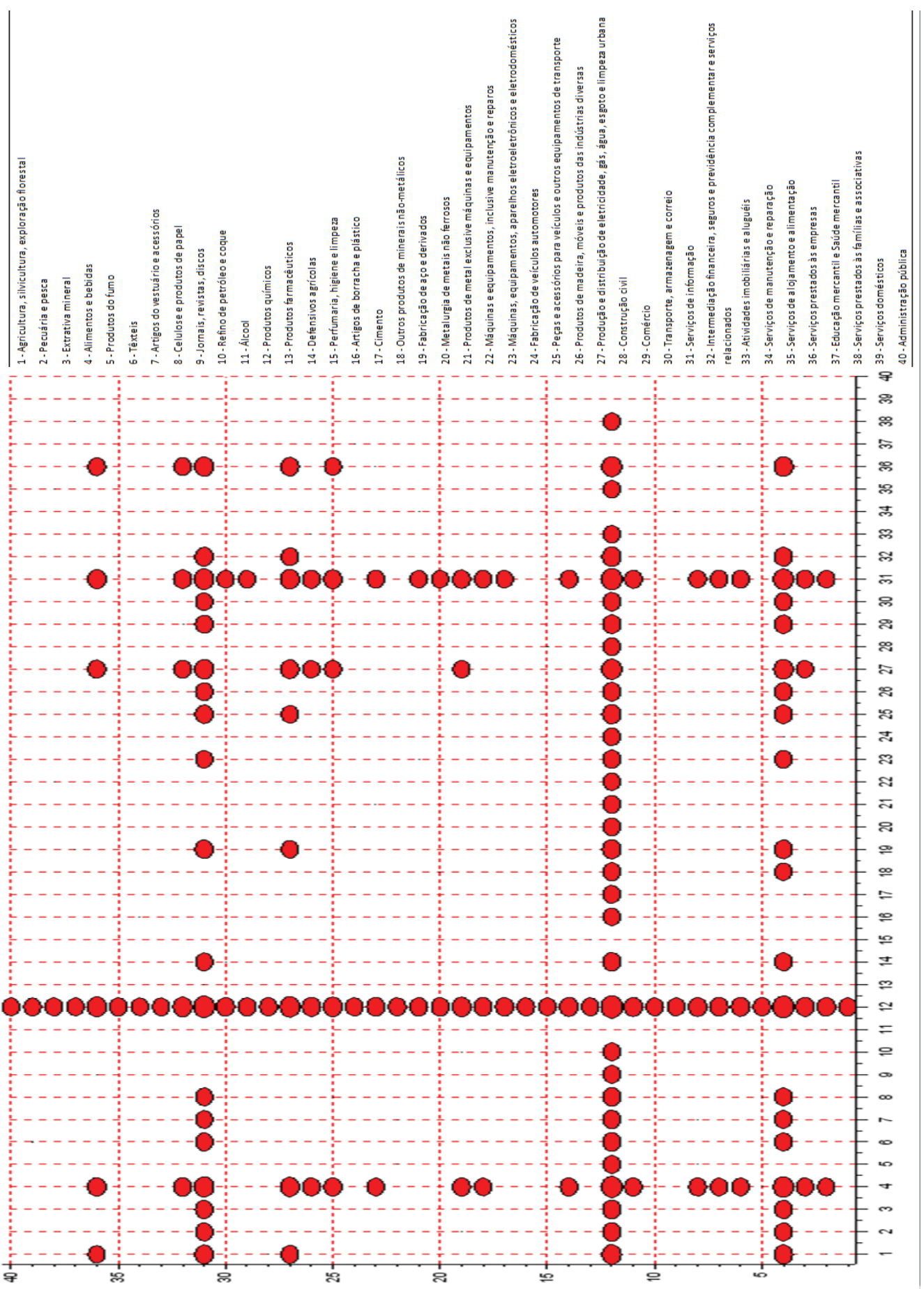




\subsection{3 Índices Puros de Ligação}

A Tabela 8 traz os valores dos índices puros de ligação para trás (PBL), para frente (PFL) e total (PTL) para cada um dos 40 setores analisados.

Tabela 8: Índices Puros de Ligação

\begin{tabular}{|c|c|c|c|c|c|c|c|}
\hline Código & Atividade & PBL & $\begin{array}{l}\text { Classificação } \\
\text { PBL }\end{array}$ & PFL & $\begin{array}{l}\text { Classificação } \\
\text { PFL }\end{array}$ & $\begin{array}{c}\text { PTL } \\
(\mathrm{PBL}+\mathrm{PFL})\end{array}$ & $\begin{array}{l}\text { Classificação } \\
\text { PTL }\end{array}$ \\
\hline 101 & $\begin{array}{l}\text { Agricultura, silvicultura, } \\
\text { exploração florestal }\end{array}$ & 5.515.288.826 & 9 & 11.724 .717 .247 & 3 & 17.240 .006 .073 & 6 \\
\hline 102 & Pecuária e pesca & 4.799 .650 .862 & 11 & 6.873 .161 .580 & 10 & 11.672 .812 .442 & 14 \\
\hline 201 & Extrativa mineral & 7.109.257.561 & 7 & 6.324 .890 .391 & 12 & 13.434 .147 .952 & 10 \\
\hline 301 & Alimentos e bebidas & 19.906 .942 .449 & 1 & 4.736 .675 .773 & 14 & 24.643 .618 .222 & 2 \\
\hline 302 & Produtos do fumo & 21.832 .873 & 39 & 9.829 .306 & 39 & 31.662 .179 & 39 \\
\hline 303 & Têxteis & 1.255 .459 .065 & 31 & 778.448 .151 & 31 & 2.033.907.216 & 32 \\
\hline 304 & $\begin{array}{c}\text { Artigos do vestuário e } \\
\text { acessórios }\end{array}$ & 1.750 .970 .108 & 26 & 235.471 .463 & 35 & 1.986 .441 .571 & 33 \\
\hline 307 & $\begin{array}{c}\text { Celulose e produtos } \\
\text { de papel }\end{array}$ & 913.702 .507 & 33 & 520.201 .980 & 33 & 1.433.904.487 & 35 \\
\hline 308 & Jornais, revistas, discos & 519.355 .679 & 36 & 1.538 .339 .424 & 25 & 2.057.695.103 & 31 \\
\hline 309 & $\begin{array}{c}\begin{array}{c}\text { Refino de petróleo e } \\
\text { coque }\end{array} \\
\end{array}$ & 2.304.494.570 & 25 & 10.231 .303 .838 & 6 & 12.535 .798 .408 & 11 \\
\hline 310 & Álcool & 1.020 .809 .711 & 32 & 727.515 .084 & 32 & 1.748 .324 .795 & 34 \\
\hline 311 & Produtos químicos & 3.369 .514 .648 & 19 & 7.521.283.644 & 9 & 10.890 .798 .292 & 16 \\
\hline 313 & Produtos farmacêuticos & 766.054 .102 & 34 & 91.830 .758 & 38 & 857.884 .859 & 37 \\
\hline 314 & Defensivos agrícolas & 352.449 .766 & 38 & 917.328 .042 & 29 & 1.269 .777 .808 & 36 \\
\hline 315 & $\begin{array}{c}\text { Perfumaria, higiene e } \\
\text { limpeza }\end{array}$ & 432.675 .790 & 37 & 117.945 .018 & 37 & 550.620 .808 & 38 \\
\hline 318 & $\begin{array}{c}\text { Artigos de borracha e } \\
\text { plástico }\end{array}$ & 1.256 .732 .720 & 30 & 2.007 .079 .784 & 19 & 3.263 .812 .504 & 27 \\
\hline 319 & Cimento & 1.308.223.153 & 29 & 1.121 .199 .089 & 28 & 2.429.422.242 & 29 \\
\hline 320 & $\begin{array}{l}\text { Outros produtos de } \\
\text { minerais não-metálicos }\end{array}$ & 2.986.295.771 & 22 & 3.395 .089 .913 & 16 & 6.381 .385 .684 & 20 \\
\hline 321 & $\begin{array}{l}\text { Fabricação de aço e } \\
\text { derivados }\end{array}$ & 17.978 .144 .520 & 2 & 5.758 .318 .721 & 13 & 23.736 .463 .240 & 3 \\
\hline 322 & $\begin{array}{l}\text { Metalurgia de metais não } \\
\text { ferrosos }\end{array}$ & 3.094.389.617 & 20 & 1.745 .275 .481 & 23 & 4.839 .665 .098 & 25 \\
\hline 323 & $\begin{array}{l}\text { Produtos de metal } \\
\text { exclusive máquinas e } \\
\text { equipamentos }\end{array}$ & 2.875 .397 .670 & 23 & 3.265 .221 .396 & 17 & 6.140 .619 .067 & 21 \\
\hline 324 & $\begin{array}{c}\text { Máquinas e } \\
\text { equipamentos, inclusive } \\
\text { manutenção e reparos }\end{array}$ & 3.372 .755 .276 & 18 & 1.468 .120 .007 & 26 & 4.840 .875 .283 & 24 \\
\hline 325 & $\begin{array}{c}\text { Máquinas, } \\
\text { equipamentos, aparelhos } \\
\text { eletroeletrônicos e } \\
\text { eletrodomésticos }\end{array}$ & 3.524 .682 .918 & 17 & 1.910 .485 .675 & 22 & 5.435 .168 .593 & 23 \\
\hline 330 & $\begin{array}{l}\text { Fabricação de veículos } \\
\text { automotores }\end{array}$ & 10.926 .940 .325 & 4 & 125.025 .246 & 36 & 11.051 .965 .570 & 15 \\
\hline
\end{tabular}


(continua)

\begin{tabular}{|c|c|c|c|c|c|c|c|}
\hline 332 & $\begin{array}{l}\text { Peças e acessórios } \\
\text { para veículos e outros } \\
\text { equipamentos de } \\
\text { transporte }\end{array}$ & 3.723 .862 .735 & 16 & 3.604 .445 .395 & 15 & 7.328 .308 .130 & 18 \\
\hline 334 & $\begin{array}{l}\text { Produtos de madeira, } \\
\text { móveis e produtos das } \\
\text { indústrias diversas }\end{array}$ & 1.579 .444 .589 & 27 & 819.693 .696 & 30 & 2.399 .138 .285 & 30 \\
\hline 401 & $\begin{array}{l}\text { Produção e distribuição } \\
\text { de eletricidade, gás, água, } \\
\text { esgoto e limpeza urbana }\end{array}$ & 2.428 .967 .934 & 24 & 9.945 .140 .753 & 7 & 12.374 .108 .687 & 12 \\
\hline 501 & Construção civil & 9.370 .056 .901 & 6 & 2.520 .869 .981 & 18 & 11.890 .926 .882 & 13 \\
\hline 601 & Comércio & 9.715 .923 .801 & 5 & 17.111 .392 .300 & 2 & 26.827.316.101 & 1 \\
\hline 701 & $\begin{array}{c}\text { Transporte, } \\
\text { armazenagem e correio }\end{array}$ & 6.948 .165 .935 & 8 & 11.096 .291 .621 & 4 & 18.044 .457 .556 & 5 \\
\hline 801 & Serviços de informação & 3.981 .816 .495 & 15 & 10.469 .676 .299 & 5 & 14.451 .492 .794 & 8 \\
\hline 901 & $\begin{array}{l}\text { Intermediação financeira, } \\
\text { seguros e previdência } \\
\text { complementar e serviços } \\
\text { relacionados }\end{array}$ & 4.436 .825 .466 & 12 & 9.536 .304 .153 & 8 & 13.973 .129 .620 & 9 \\
\hline 1001 & $\begin{array}{c}\text { Atividades imobiliárias e } \\
\text { aluguéis }\end{array}$ & 1.404 .747 .521 & 28 & 6.627 .192 .409 & 11 & 8.031 .939 .931 & 17 \\
\hline 1101 & $\begin{array}{l}\text { Serviços de manutenção } \\
\text { e reparação }\end{array}$ & 554.846 .639 & 35 & 1.955 .191 .386 & 21 & 2.510 .038 .025 & 28 \\
\hline 1102 & $\begin{array}{c}\text { Serviços de alojamento e } \\
\text { alimentação }\end{array}$ & 4.832 .473 .689 & 10 & 1.986 .396 .125 & 20 & 6.818 .869 .814 & 19 \\
\hline 1103 & $\begin{array}{l}\text { Serviços prestados às } \\
\text { empresas }\end{array}$ & 3.063 .219 .697 & 21 & 17.507 .967 .200 & 1 & 20.571 .186 .897 & 4 \\
\hline 1104 & $\begin{array}{l}\text { Educação mercantil e } \\
\text { saúde mercantil }\end{array}$ & 4.064 .304 .077 & 14 & 313.868 .812 & 34 & 4.378 .172 .889 & 26 \\
\hline 1106 & $\begin{array}{l}\text { Serviços prestados às } \\
\text { famílias e associativas }\end{array}$ & 4.326 .476 .755 & 13 & 1.598 .081 .663 & 24 & 5.924 .558 .418 & 22 \\
\hline 1107 & Serviços domésticos & 0 & 40 & 0 & 40 & 0 & 40 \\
\hline 1203 & Administração pública & 13.996.727.180 & 3 & 1.272 .966 .362 & 27 & 15.269 .693 .542 & 7 \\
\hline
\end{tabular}

A influência do nível de produção sobre os índices puros de ligação pode ser confirmada por meio da comparação da classificação PTL dos setores e seus respectivos valores de produção. Dos sete setores com maiores índices PTL ("Comércio", "Alimentos e bebidas", "Fabricação de aço e derivados", "Serviços prestados às empresas", "Transporte, armazenagem e correio", "Agricultura, silvicultura e exploração florestal" e "Administração pública"), apenas o setor de "Serviços prestados às empresas" não possui um dos sete maiores valores brutos de produção (VBP), como mostrado na Tabela 9. Esse fato pode ser explicado pelo alto grau de encadeamento desse setor se comparado aos outros setores com VBP equivalente. 
Tabela 9: Setores com maiores PTL e seus valores brutos de produção

\begin{tabular}{c|c|c|c|c|c}
\hline Código & Atividade & $\begin{array}{c}\text { PTL } \\
\text { PBL+PFL) }\end{array}$ & $\begin{array}{c}\text { classificação } \\
\text { PTL }\end{array}$ & VBP & $\begin{array}{c}\text { classificação } \\
\text { VBP }\end{array}$ \\
\hline 101 & $\begin{array}{c}\text { Agricultura, silvicultura, } \\
\text { exploração florestal }\end{array}$ & 17.240 .006 .073 & 6 & 22.915 .881 .046 & 7 \\
\hline 301 & Alimentos e bebidas & 24.643 .618 .222 & 2 & 32.256 .114 .099 & 4 \\
\hline 321 & $\begin{array}{c}\text { Fabricação de aço e } \\
\text { derivados }\end{array}$ & 23.736 .463 .240 & 3 & 41.236 .087 .541 & 2 \\
\hline 601 & Comércio & 26.827 .316 .101 & 1 & 40.249 .739 .275 & 3 \\
\hline 701 & $\begin{array}{c}\text { Transporte, } \\
\text { armazenagem e correio }\end{array}$ & 18.044 .457 .556 & 5 & 24.142 .233 .403 & 5 \\
\hline 1103 & $\begin{array}{c}\text { Serviços prestados às } \\
\text { empresas }\end{array}$ & 20.571 .186 .897 & 4 & 16.194 .208 .277 & 13 \\
\hline 1203 & Administração pública & 15.269 .693 .542 & 7 & 47.074 .222 .147 & 1 \\
\hline
\end{tabular}

De forma análoga, dos sete setores com menores índices PTL (“Serviços domésticos", "Produtos do fumo", "Perfumaria, higiene e limpeza", "Produtos farmacêuticos", "Defensivos agrícolas", "Celulose e produtos de papel” e "Álcool”), apenas os setores de "Serviços domésticos" e "Celulose e produtos de papel" não possuem um dos sete menores valores brutos de produção (VBP), como mostrado na Tabela 10. Esse fato pode ser facilmente explicado para o setor de "Serviços domésticos", que apresenta coeficientes iguais a zero na matriz de coeficientes diretos, e pelo baixo grau de encadeamento apresentado pelo setor de "Celulose e produtos de papel” se comparado a outros setores com VBP equivalente.

Tabela 10: Setores com menores PTL e seus valores brutos de produção

\begin{tabular}{|c|c|c|c|c|c|}
\hline Código & Atividade & $\begin{array}{c}\text { PTL } \\
(\mathrm{PBL}+\mathrm{PFL})\end{array}$ & $\begin{array}{c}\text { classificação } \\
\text { PTL }\end{array}$ & VBP & $\begin{array}{c}\text { classificação } \\
\text { VBP }\end{array}$ \\
\hline 302 & Produtos do fumo & 31.662 .179 & 39 & 1.118 .856 .012 & 38 \\
\hline 307 & $\begin{array}{c}\text { Celulose e produtos } \\
\text { de papel }\end{array}$ & 1.433 .904 .487 & 35 & 2.662.156.949 & 33 \\
\hline 310 & Álcool & 1.748 .324 .795 & 34 & 1.391 .113 .721 & 36 \\
\hline 313 & $\begin{array}{c}\text { Produtos } \\
\text { farmacêuticos }\end{array}$ & 857.884 .859 & 37 & 1.288 .182 .970 & 37 \\
\hline 314 & Defensivos agrícolas & 1.269 .777 .808 & 36 & 735.503 .928 & 40 \\
\hline 315 & $\begin{array}{c}\text { Perfumaria, higiene e } \\
\text { limpeza }\end{array}$ & 550.620 .808 & 38 & 835.321 .825 & 39 \\
\hline 1107 & Serviços domésticos & 0 & 40 & 3.269 .018 .229 & 30 \\
\hline
\end{tabular}




\subsubsection{Comparação dos índices}

Dadas as diferentes características metodológicas dos índices, é natural que os resultados não fossem completamente convergentes. No entanto, isso não é encarado como um problema, já que os índices de Rasmussen-Hirschman, campos de influência e os índices puros de ligação não são vistos como excludentes, mas complementares. Dito isso, a Tabela 11 resume os resultados obtidos nos tópicos anteriores.

Tabela 11: Resumo dos setores-chave de 2008.

\begin{tabular}{c|c}
\hline & Índices de Rasmussen-Hirschman \\
\hline 201 & Extrativa mineral \\
\hline 301 & Alimentos e bebidas \\
\hline 311 & Produtos químicos \\
\hline 821 & Fabricação de aço e derivados \\
\hline \multicolumn{2}{|c}{ Serviços de informação } \\
\hline 301 & Campo de Influência \\
\hline 311 & Alimentos e bebidas \\
\hline 801 & Produtos químicos \\
\hline 401 & Serviços de informação \\
\hline 1103 & Srodução e distribuição de eletricidade, gás, água, esgoto e limpeza urbana \\
\hline 301 & Serviços prestados às empresas \\
\hline 321 & Índices Puros de Ligação \\
\hline 601 & Alimentos e bebidas \\
\hline 701 & Fabricação de aço e derivados \\
\hline 1103 & Comércio \\
\hline
\end{tabular}

Destaca-se a presença do setor de "Alimentos e bebidas" como setor-chave nas três metodologias abordadas. "Produtos químicos" e "Serviços de informação" apareceram como setores-chave pelos índices de Rasmussen-Hirschman e campos de influência, que se concentram mais no fator interno da economia. Já os setores de "Fabricação de aço e derivados" e "Serviços prestados às empresas", que já haviam aparecido em um dos dois primeiros métodos, aparecem, também, como setor-chave pelo índice puro de ligação, que leva em consideração o nível de produção. "Extrativa mineral", "Produção e distribuição de eletricidade, gás, água, esgoto e limpeza urbana" e "Comércio" e "Transporte, armazenagem e correio" aparecem apenas em uma das três metodologias empregadas. 
Como mencionado na introdução deste trabalho, a agregação setorial da economia mineira, utilizada na construção da matriz de insumo-produto para o ano de 2008 é diferente das agregações escolhidas tanto para 1996 quanto para 2005. Essa diferença metodológica limita a capacidade de comparação entre os resultados observados. O setor de "Alimentos e bebidas", por exemplo, havia sido desmembrado em dois setores distintos nos estudos anteriores, a saber, "Alimentos" e "Bebidas", o que contribuiu para que tal atividade não fosse considerada um setor-chave. Ainda assim, os resultados se mostraram coerentes, com setores como "Produtos Químicos", "Extrativa Mineral" e "Comércio" também se destacando nos trabalhos de construção da MIP para 1996 e 2005. A atividade "Serviços prestados às empresas" surgiu como um setor chave em dois métodos, o que pode ser interpretado como um indicativo de mudança em direção a um maior peso dos serviços, que já compõem a maior parte do produto interno bruto de Minas Gerais.

\subsection{Multiplicadores}

Os multiplicadores de impacto sobre a renda do trabalho, emprego e valor adicionado foram construídos a partir da matriz de insumo-produto de Minas Gerais, de 2008. Com esses multiplicadores é possível observar os setores de maior influência na economia nas variáveis citadas.

Os setores que possuem os maiores valores nos multiplicadores totais de renda do trabalho são atividades dos serviços (Figura 1). A atividade de "Serviços domésticos” gera o maior multiplicador: um aumento de $\mathrm{R} \$ 1.288 .461$ na renda do trabalho diante do aumento de um milhão de reais na demanda final. O segundo setor com maior multiplicador total é a "Administração pública”, seguido pela "Educação mercantil e saúde mercantil". A "Pecuária e pesca" possui o quinto maior multiplicador e na indústria destaca-se o setor de "Álcool" e "Alimentos e bebidas". Um aumento nos investimentos em Minas Gerais que resultasse na expansão da produção de Álcool em um milhão de reais resultaria em uma ampliação na renda do trabalho de mais de $\mathrm{R} \$ 417.000$.

Em termos de efeitos diretos sobre a economia, destacam-se os setores de "Alimentos e bebidas", “Álcool”, "Produtos farmacêuticos”, "Cimento" e "Serviços de informação". Um aumento do investimento na produção de produtos farmacêuticos de um milhão de reais resultaria em uma ampliação na renda do trabalho, superior a $\mathrm{R} \$ 70.000$, nos setores que fornecem insumos diretamente para sua produção.

No caso do emprego, os serviços se destacam com elevados multiplicadores. A atividade de "Serviços domésticos" apresenta o maior multiplicador: 285 empregos a mais diante de um aumento da demanda final de um milhão de reais (Figura 2). O setor de "Artigos de vestuário e acessórios" aparece com o segundo maior multiplicador. Com um estímulo na demanda final da economia de um milhão de reais, estima-se que o setor de "Artigos de vestuário e acessórios" geraria 99 empregos. Os setores com maiores multiplicadores de emprego direto são "Álcool”, "Alimentos e bebidas", "Artigos do vestuário e acessórios" e "Têxteis". 
Figura 1: Multiplicador total da renda do trabalho por atividade para uma variação na demanda final de um milhão de reais - Minas Gerais - 2008.

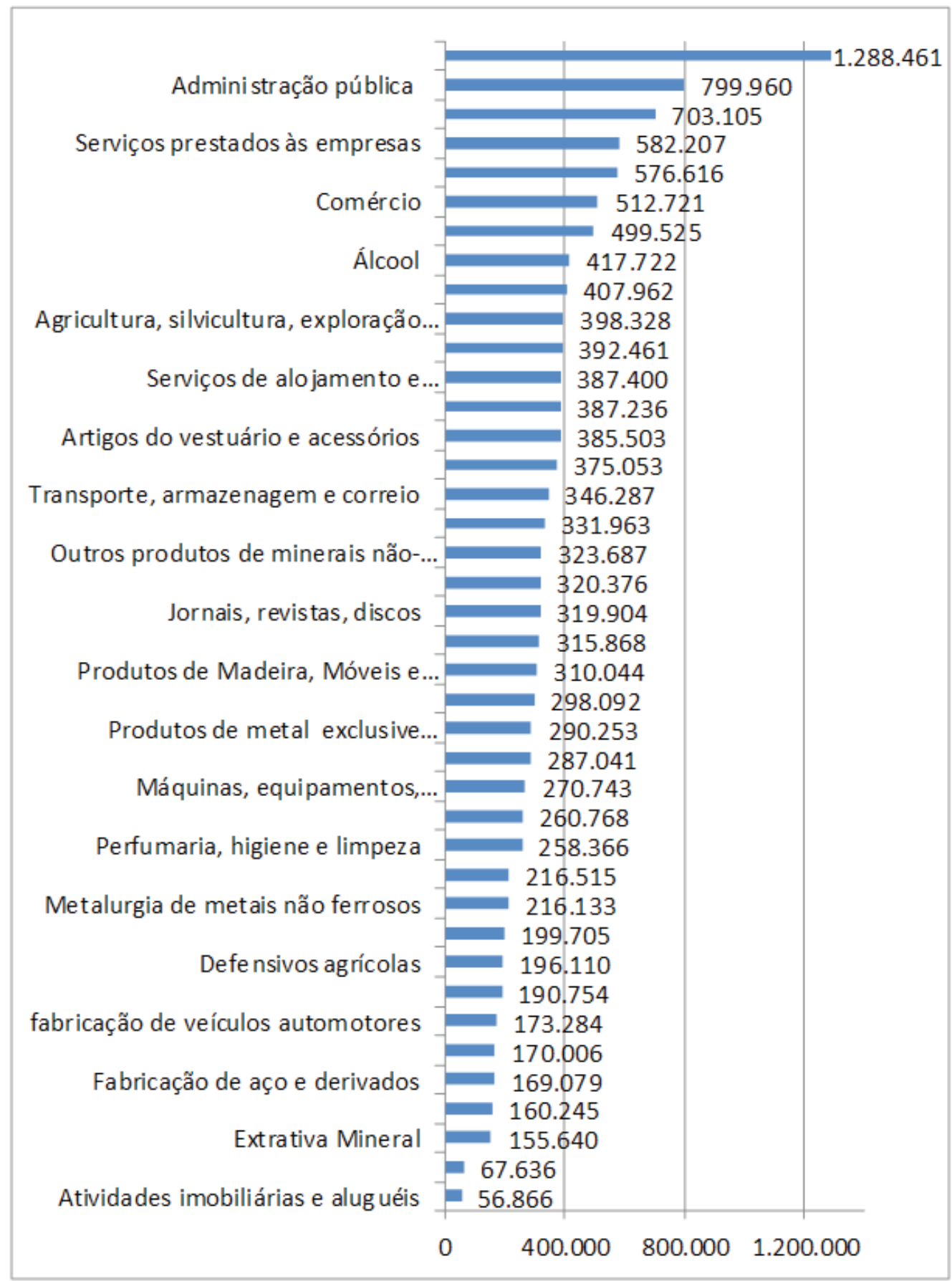


Figura 2: Multiplicador total de emprego por atividade para uma variação na demanda final de um milhão de reais - Minas Gerais - 2008.

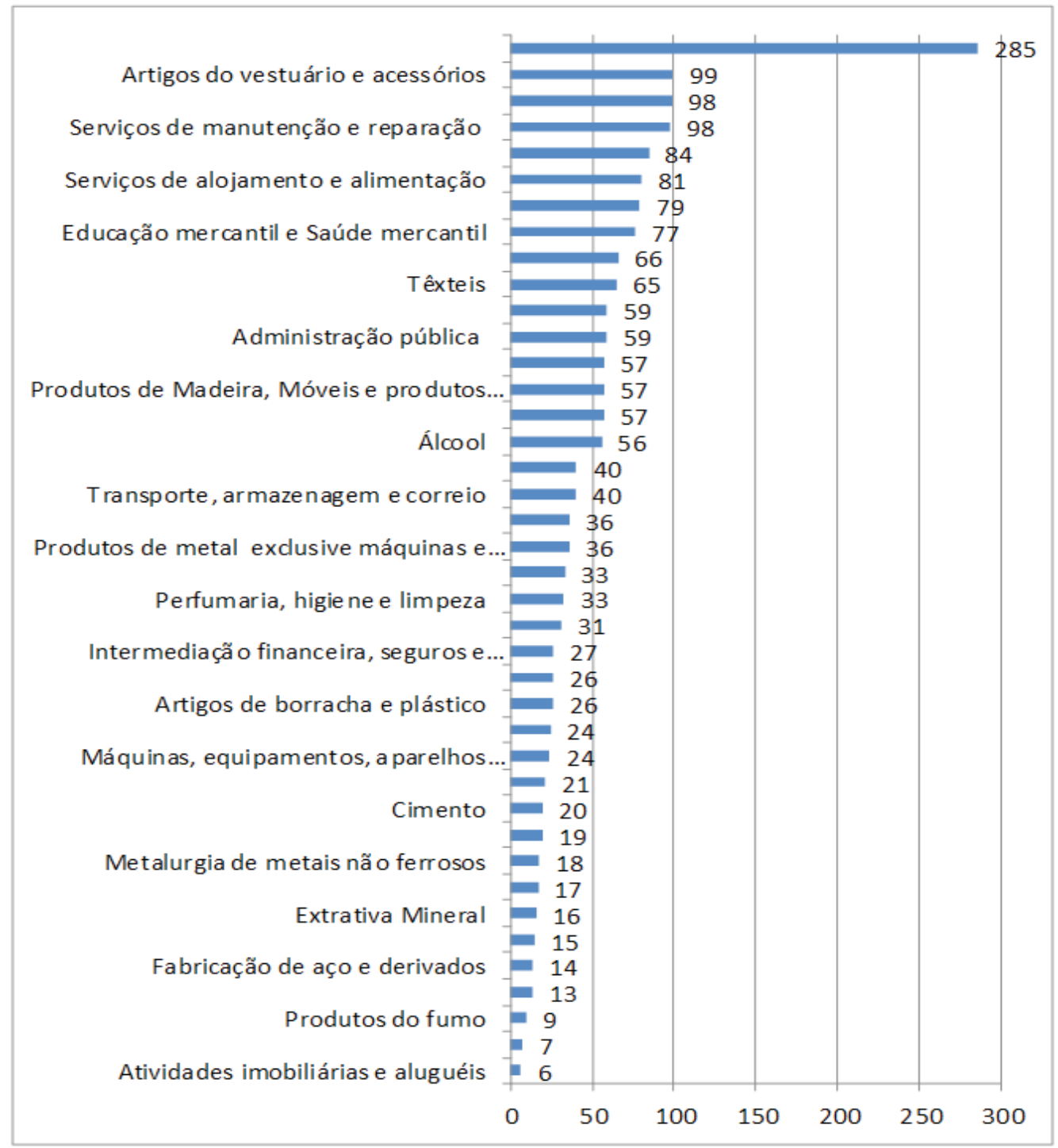

As atividades de "Serviços domésticos", de "Administração pública", de "Pecuária e pesca", de "Serviços de manutenção e reparação" e de "Comércio" possuem os maiores multiplicadores do valor adicionado. Na indústria, o maior multiplicador está na atividade de "Álcool".

Com relação ao multiplicador do ICMS, o maior multiplicador seria do setor "Refino de petróleo e coque", "Produtos do fumo", "Serviços de informação" e "Cimento". Em termos de multiplicador direto, os setores que se destacam são: 
"Cimento", "Transporte, armazenagem e correio", "Serviços de informação" e "Outros produtos minerais não metálicos". Por exemplo, um aumento da demanda final de um milhão de reais geraria uma arrecadação de quase $\mathrm{R} \$ 54.000$.

No caso do IPI, destacam-se os setores "Produtos do Fumo", "Perfumaria, higiene e limpeza" e "Fabricação de veículos automotores". Os setores com maior multiplicador direto são, além de "Produtos do Fumo", as atividades de "Produtos de madeira, móveis e produtos das indústrias diversas", "Construção civil" e "Fabricação de veículos automotores”.

Figura 3: Multiplicador total de valor adicionado por atividade para uma variação na demanda final de um milhão de reais - Minas Gerais - 2008.

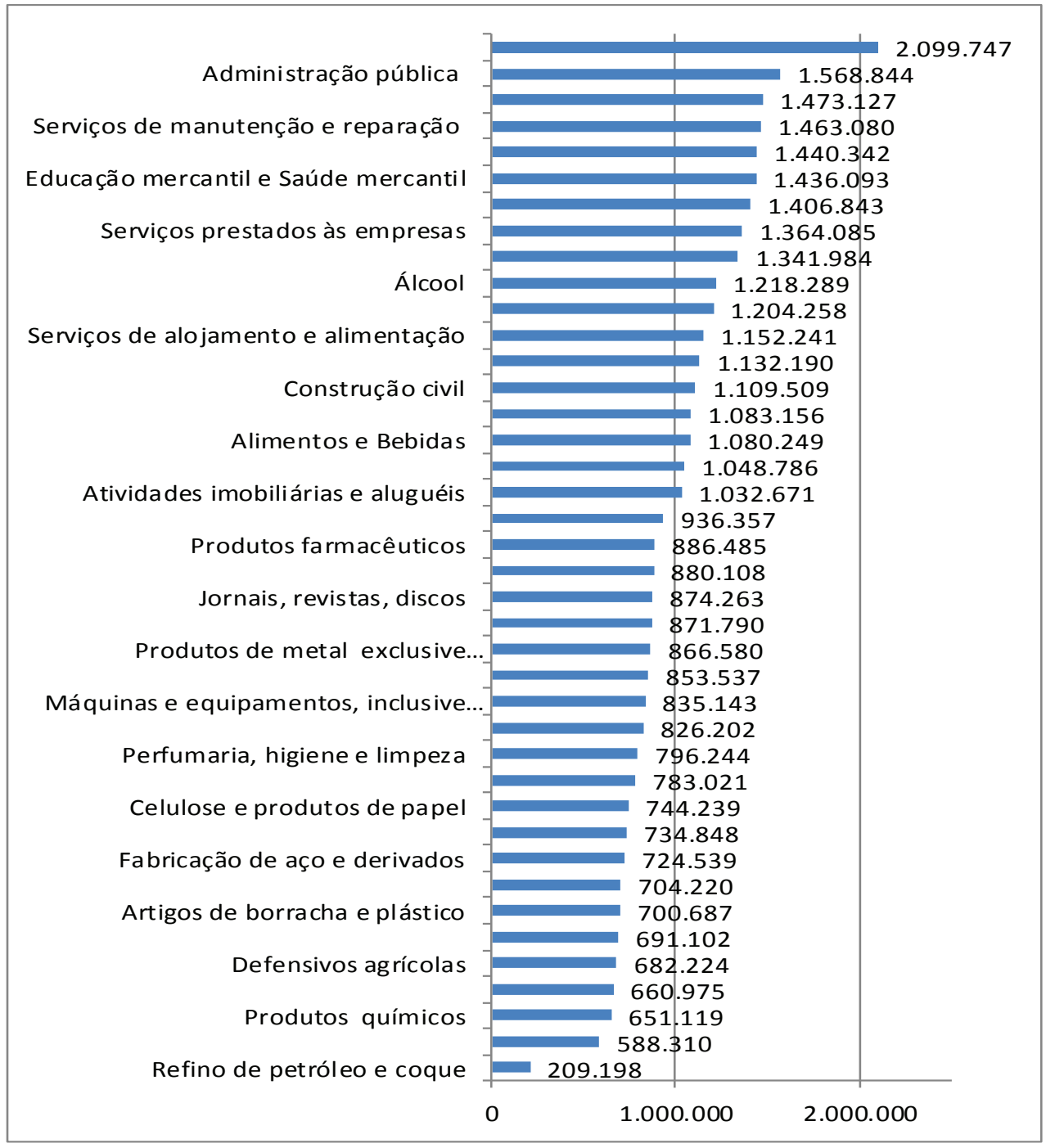


Figura 4: Multiplicador total de ICMS por atividade para uma variação na demanda final de um milhão de reais - Minas Gerais - 2008.

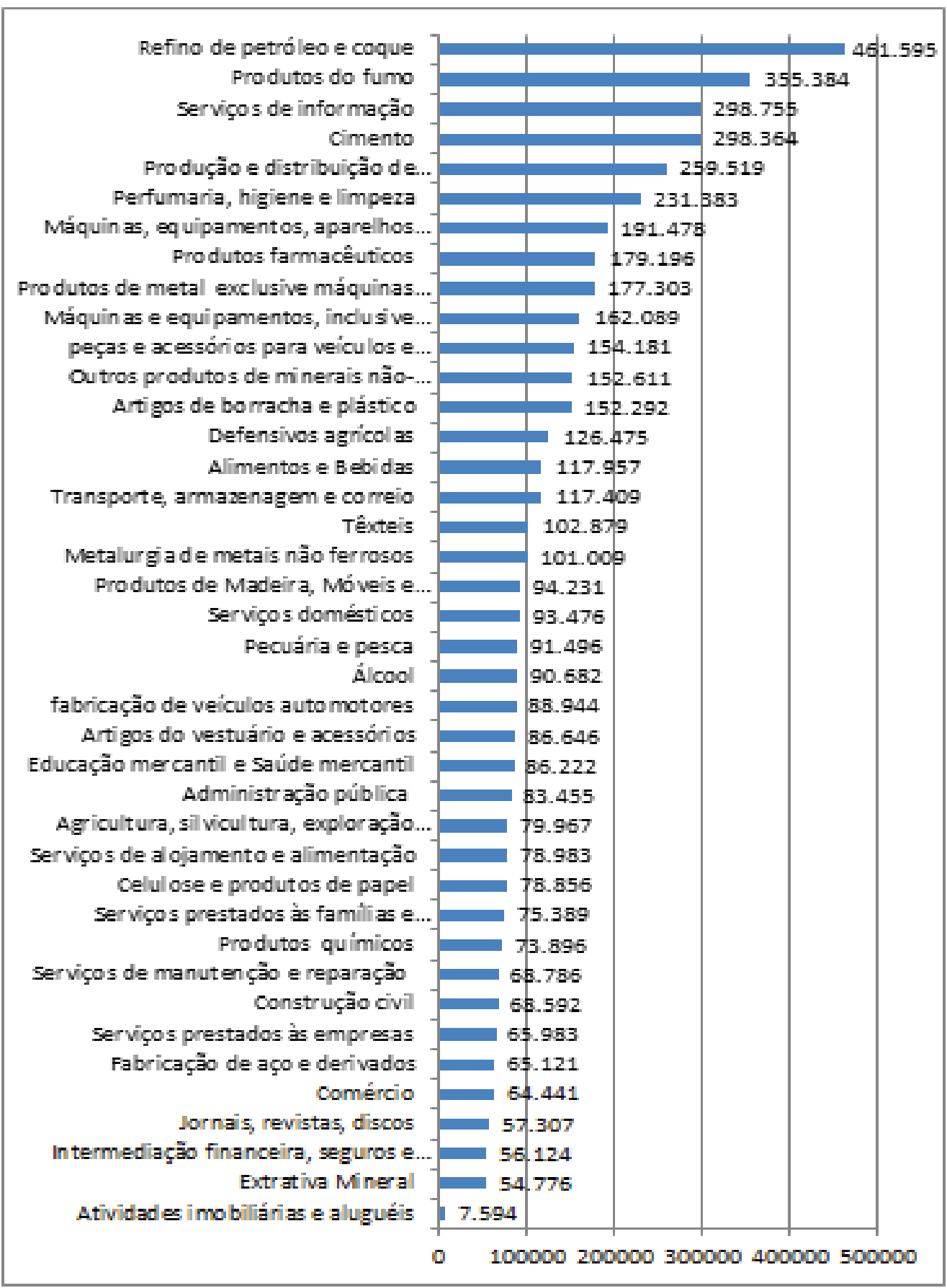


Figura 5: Multiplicador total de IPI por atividade para uma variação na demanda final de um milhão de reais - Minas Gerais - 2008.

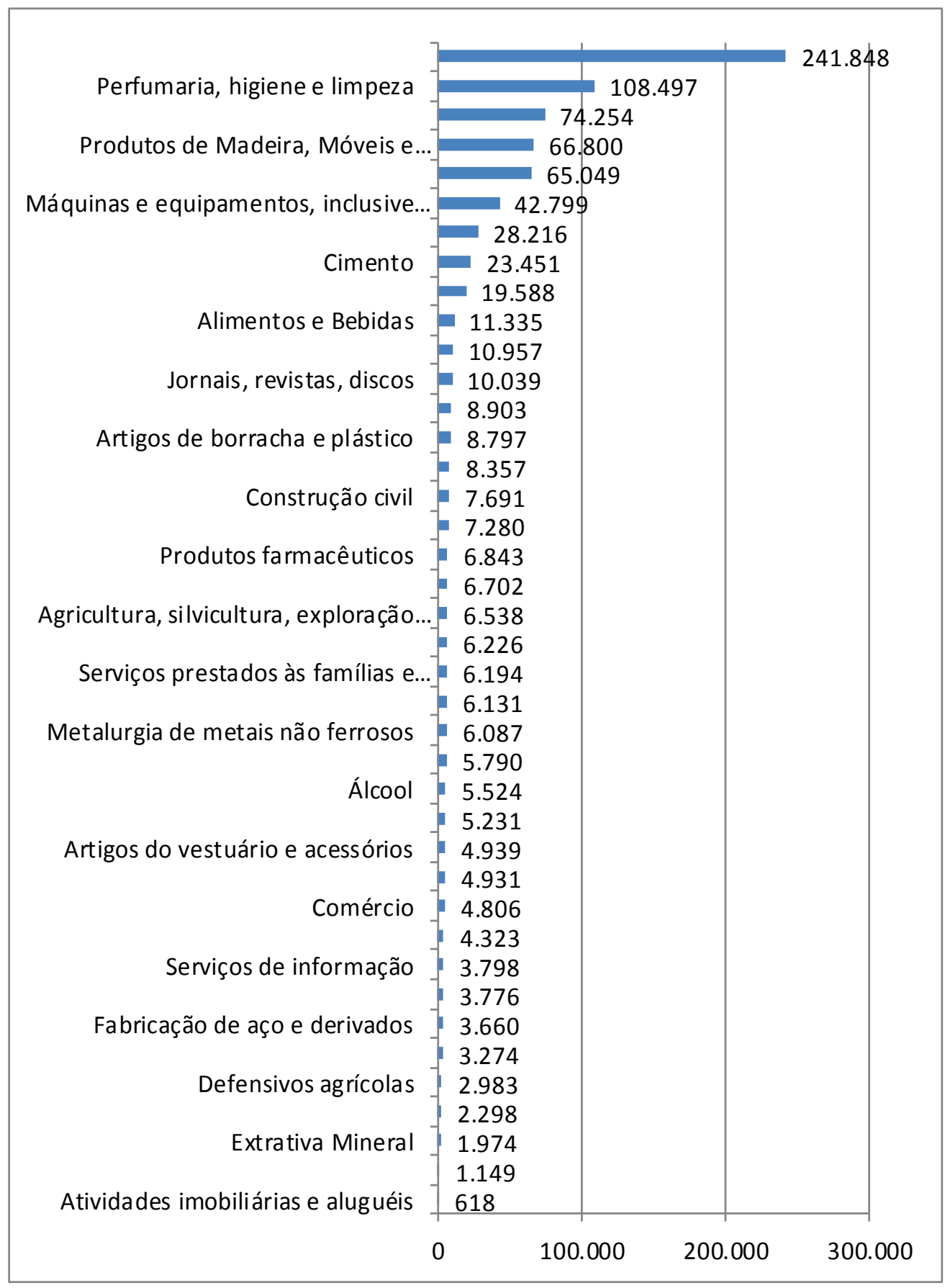




\section{Conclusão}

Este trabalho teve como objetivo identificar setores-chave da economia mineira, para o ano de 2008, assim como analisar o impacto dos diversos setores via cálculo dos multiplicadores. A partir da MIP de 2008 e dos modelos aberto e fechado, de Leontief, foi possível apontar setores-chave com base em três metodologias diferentes: índices de interligação de Rasmussen-Hirschman, campos de influência e índices puros de ligação. Em relação aos multiplicadores, foram abordados os impactos sobre a renda do trabalho, emprego, valor adicionado e impostos (ICMS e IPI).

Por meio dos resultados obtidos, foi possível identificar setores-chave e elencá-los de acordo com sua influência sobre as demais atividades econômicas de Minas Gerais, seja por meio de seus efeitos internos (via índices de interligação de Rasmussen-Hirschman e campos de influência), seja por meio de seu nível de produção (via índices puros de ligação). Setores como "Alimentos e bebidas", "Produtos químicos", "Serviços de informação", "Fabricação de aço e derivados" e "Serviços prestados às empresas" se destacaram em mais de um método de cálculo.

É interessante tomar como exemplo os resultados do setor "Produtos químicos" à luz da utilidade da identificação de setores-chave no processo de formulação de políticas públicas. Considerado um setor-chave pelos métodos dos índices de interligação de Rasmussen-Hirschman e campos de influência, tanto em seu poder de dispersão quanto em sua sensibilidade à dispersão, poderiam justificar incentivos ao setor, contribuindo para a diversificação da economia e para o progresso tecnológico no Estado. A expansão do nível de produção do setor poderia torná-lo mais relevante para a economia também do ponto de vista dos índices puros de ligação.

Os resultados relacionados à metodologia dos multiplicadores evidenciaram a importância dos serviços sobre a renda do trabalho, sobre o emprego e sobre o valor adicionado, principalmente dos setores "Serviços domésticos" e "Administração pública”. Isso é esperado, uma vez que são atividades intensivas em trabalho e, portanto, mais sensíveis ao efeito induzido. No entanto, essa característica não se confunde com a classificação quanto a setor-chave, que implica na capacidade de efeitos de encadeamentos para frente e para trás.

Ressalta-se que os efeitos multiplicadores da renda e do emprego em atividades, como "Extrativa mineral", "Fabricação de aço e derivados" e "Fabricação de veículos automotores", são baixos devido à sua alta intensidade em capital, apesar de serem relevantes na estrutura produtiva mineira.

Já em relação aos multiplicadores do ICMS e IPI, destaca-se o papel da indústria, especialmente dos setores de transformação, como "Produtos do fumo", "Refino de petróleo e coque" e "Perfumaria, higiene e limpeza".

Finalmente, deve-se observar que, se o objetivo de uma política for o crescimento econômico, os setores-chave seriam os principais alvos de tais políticas. Caso o objetivo seja o estímulo de emprego e renda, seriam mais indicados os setores nos quais ocorreram os maiores efeitos multiplicadores dessas variáveis. Ao identificar e classificar os setores para cada uma dessas situações, o artigo contribui para o sucesso de tais políticas. 


\section{Referências}

FEIJÓ, C.A.; RAMOS, R.L.O. (Orgs.) Contabilidade Social: a nova referência das Contas Nacionais do Brasil. 4. ed. Rio de Janeiro: Campus Elsevier, 2013.

FERNANDES, C. L. L.; ROCHA, R. B. Os setores-chave da economia de Minas Gerais: uma análise a partir das matrizes de insumo produto de 1996 e 2005. In: SEMINÁRIO SOBRE A ECONOMIA MINEIRA, 14., 2010, Diamantina. Textos... Belo Horizonte: Universidade Federal de Minas Gerais, 2010.

FUNDAÇÃO JOÃO PINHEIRO - FJP. Tabela de recursos e Usos e Matriz de Insumo-Produto de Minas Gerais - 2008. Belo Horizonte, 2015.

GUILHOTO, J. M. M.; SONIS, M.; HEWINGS, G.J.D; MARTINS, E.B. Índices de ligações e setores-chave na economia brasileira: 1959/80. Pesquisa e Planejamento Econômico, v. 24, p. 287-314, 1994.

HADDAD, E. A. Regional inequality and structural changes: lessons from the brazilian experience. Aldershot: Ashgate, 1999.

HIRSCHMAN, A. O. HIRSCHMAN, A. O. The strategy of economic development. New Haven: Yale University Press, 1958.

KALLUF, S. N., KURESKI, R. 'Modelo insumo-produto: uma aplicação para a economia paranaense. (Nota Técnica IPARDES n. 25) Curitiba: Instituto Paranaense de Desenvolvimento Econômico e Social, 2014.

LEONTIEF, W. Quantitative Input-Output Relations in the Economic System of the United States. Reviere of Economics and Statistics, v. 18, p. 105-125, 1936. crossref https://doi.org/10.2307/1927837

LEONTIEF, W. The Structure of American Economy 1919-1939. New York: Oxford University Press, 1941.

MILLER, R. E.; BLAIR, P. D. Input-Output Analysis: foundations and extensions. 2. ed. Cambridge University Press, 2009. crossref https://doi.org/10.1017/CBO 9780511626982

MONTOYA, M. A. (org.). Relações intersetoriais do Mercosul e da economia brasileira: uma abordagem de equilíbrio geral do tipo insumo-produto. Passo Fundo: Ediuf, 1998. 
NAJBERG, S.; VIEIRA, S. P. Emprego e crescimento econômico: uma contradição? (Texto para Discussão n. 48) Rio de Janeiro: BNDES, 1996. 70 p.

PORSSE, A.A. Multiplicadores de impacto na economia gaúcha: aplicação do modelo de insumo-produto fechado de Leontief. (Documentos FEE n. 52) Porto Alegre: Fundação de Economia e Estatística Siegfried Emanuel Heuser, 2002.

RAMOS, L. P. S. Gastos com educação no Paraná: uma análise insumo-produto. Dissertação (Mestrado em Desenvolvimento Econômico) - Universidade Federal do Paraná, Curitiba, 2011, 114 f.

RASMUSSEN, P. N. Studies in inter-sectoral relations. Amsterdam: North Holland, 1956.

SONIS, M.; HEWINGS, G.J.D. Error and sensitivity input-output analysis: a new approach. In: MILLER, R.E., POLENSKE, K.R. ROSE, A.Z. (Orgs.) Frontiers of input-output analysis. New York: Oxford University Press, 1989.

Recebido em 25.05.16

Aprovado em 24.11.16 